\title{
ALTERAÇÕES NAS PROPRIEDADES DE UM PODZÓLICO VERMELHO-AMARELO RESULTANTES DA SUBSTITUIÇÃO DA MATA NATURAL PELA CULTURA DA LARANJA
}

\author{
ANDRÉA CRISTIANE SANCHES \\ Engenheira Agrônoma
}

Orientador: Prof. Dr. ÁLVARO PIRES DA SILVA

\begin{abstract}
Dissertação apresentada à Escola Superior de Agricultura "Luiz de Queiroz", Universidade de São Paulo, para obtenção do título de Mestre em Agronomia, Área de Concentração: Solos e Nutrição de Plantas.
\end{abstract}

PIRACICABA

Estado de São Paulo - Brasil

Janeiro - 1998 
Dados Internacionais de Catalogação na Publicação (CIP)

DIVISĀO DE BIBLIOTECA E DOCUMENTACÁO - Campus "Luiz de Oueiroz"/USP

Sanches, Andréa Cristiane

Alteraçōes nas propriedades de um podzólico vermelho-amarelo resultantes da substituição da mata natural pela cultura da laranja / Andréa Cristiane Sanches. - Piracicaba, 1998.

$49 \mathrm{p}$.

Dissertação (mestrado) - Escola Superior de Agricultura Luiz de Queiroz, 1998.

Bibliografia.

1. Citricultura 2. Impacto ambiental 3. Microbiologia do solo 4. Propriedade fisico-quimica do solo I. Titulo

CDD 631.41 


\section{ALTERAÇÕES NAS PROPRIEDADES DE UM PODZÓLICO VERMELHO-AMARELO RESULTANTES DA SUBSTITUIÇÃO DA MATA NATURAL PELA CULTURA DA LARANJA}

ANDRÉA CRISTIANE SANCHES

Aprovada em : 18.02.1998

Comissão julgadora:

Prof. Dr. Álvaro Pires da Silva

Prof. Dr. Luiz Reynaldo Ferracciú Alleoni

Dr. Sérgio Alves de Carvalho
ESALQ/USP ESALQ / USP $\mathrm{CCSM} / \mathrm{IAC}$

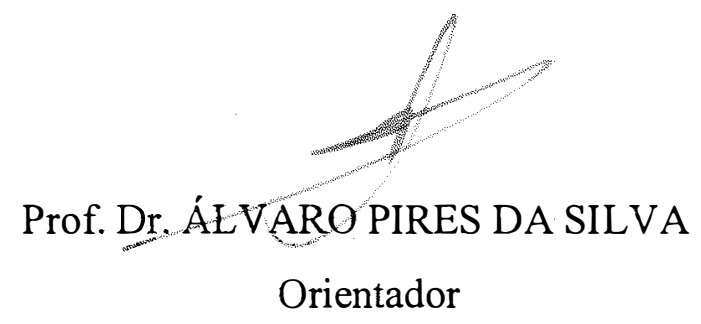


Aos meus pais José Roberto e Lúcia e minhas irmãs Giseli e Ana Lúcia DEDICO 


\section{AGRADECIMENTOS}

- Ao Prof. Dr. Álvaro Pires da Silva, pela orientação e amizade.

- À Escola Superior de Agricultura "Luiz de Queiroz", particularmente à Coordenação do Curso de Pós-Graduação em Solos e Nutrição de Plantas, pela oportunidade de realizar este trabalho.

- À Cambuhy Agrícola Ltda., pelas informações cedidas e contribuição na coleta de amostras.

- À Dra. Marli de Fátima Fiori (CENA), pela orientação e colaboração na realização das análises microbiológicas.

- Ao CNPq, pela bolsa de estudos.

- Aos amigos Cássio A. Tormena, Silvia Imhoff e, em especial, à Vládia Correchel pelo incansável apoio durante a realização deste trabalho.

- À Fernanda, Adriana, Telma e Andréa, pela amizade. 


\section{SUMÁRIO}

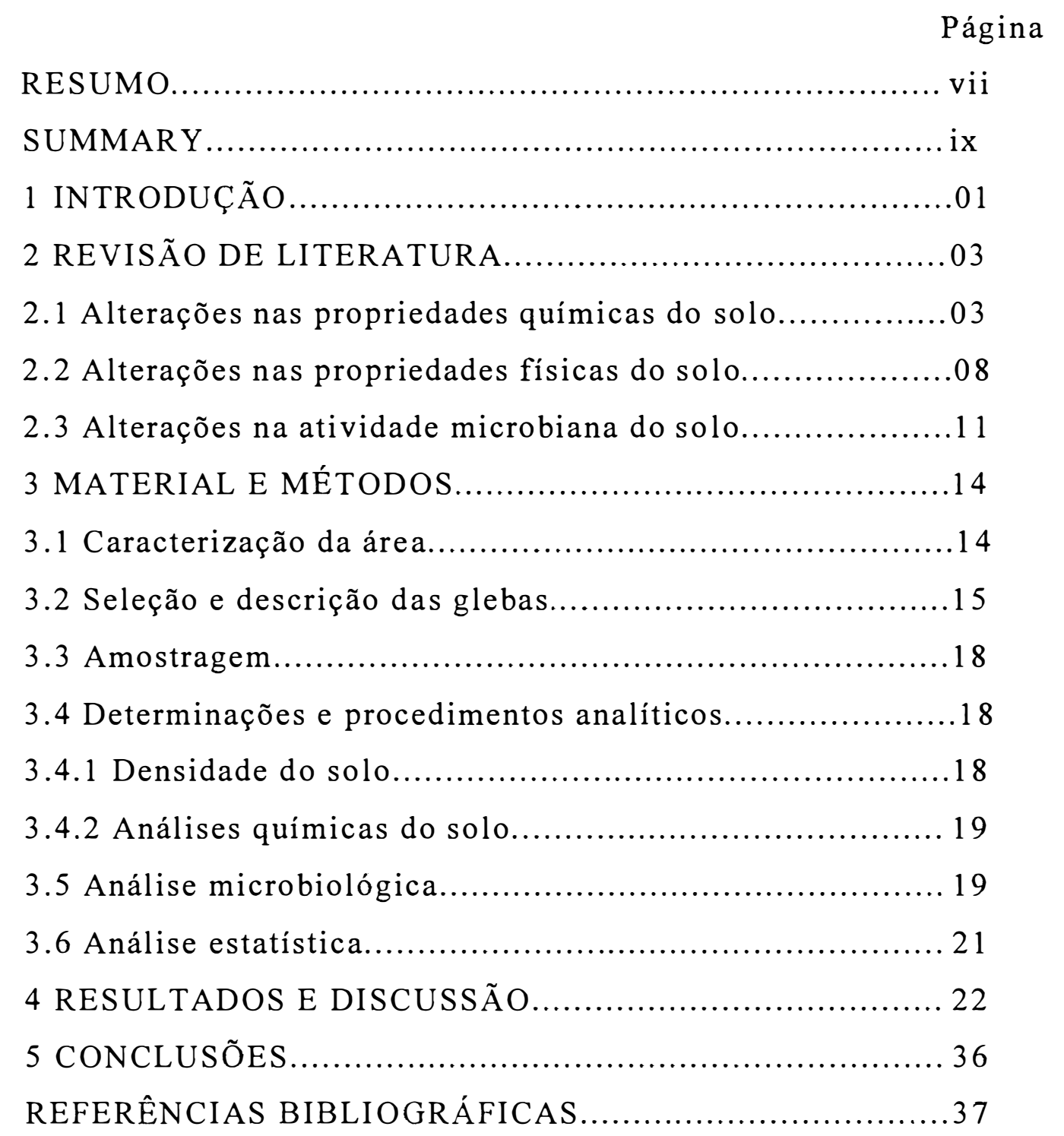




\title{
ALTERAÇÕES NAS PROPRIEDADES DE UM PODZÓLICO VERMELHO-AMARELO RESULTANTES DA SUBSTITUIÇĀO DA MATA NATURAL PELA CULTURA DA LARANJA
}

\author{
Autor: ANDRÉA CRISTIANE SANCHES \\ Orientador: Prof. Dr. ÁlVARO PIRES DA SILVA
}

RESUMO

A substituição das matas naturais por culturas agrícolas causa modificações nas propriedades do solo. Neste estudo foram quantificadas as alterações nas propriedades físicas químicas e microbiológicas do solo após dezoito anos da retirada da vegetação natural e implantação da cultura da laranja. Foram estudadas, também, a intensidade da alteração para cada parâmetro e a influência da posição da cultura relativa a linha de plantio. As amostragens foram realizadas na fazenda Cambuhy, no Município de Matão - SP, em áreas próximas cultivadas com laranja e sob mata natural, em um podzólico vermelho-amarelo. As amostras foram retiradas em pontos distribuídos na projeção da copa das plantas, na entrelinha da cultura e na mata, nas profundidades 0-20 e 20-40 $\mathrm{cm}$, determinando-se o $\mathrm{pH}$ em $\mathrm{CaCl}_{2}, \mathrm{P}$-resina, matéria orgânica, densidade do solo e atividade microbiana, e calculando-se a CTC e o V\%. As comparações foram feitas através de teste $t$ para amostras independentes, entre a mata $\mathrm{e}$ a posição da projeção da copa das plantas, e entre mata e entrelinha da cultura. A intensidade das alterações causadas pelo cultivo foi diferente para cada variável analisada e dependente da posição considerada em relação a linha de plantio. A retirada da mata e implantação da cultura da laranja alterou as propriedades físicas, químicas e microbiológicas do solo, principalmente na camada $0-20 \mathrm{~cm}$, com intensidade diferente 
para cada variável analisada e dependente da posição considerada em relação à linha de plantio. O cultivo provocou redução no $\mathrm{pH}$, na saturação por bases, no teor de matéria orgânica, na CTC do solo e na atividade microbiana e aumento do teor de P na projeção da copa das plantas e da densidade do solo nas duas posições estudadas. A estrutura do solo, quantificada através da densidade do solo, foi a variável mais alterada pelo cultivo, seguida da CTC e teor de matéria orgânica. 


\title{
THE EVALUATION OF SOME SOIL PROPERTIES OF A ULTISOL CULTIVATED WITH ORANGE FOR EIGTHEEN YEARS
}

\author{
Author: Andréa Cristiane Sanches \\ Adviser: Prof. Dr. Álvaro Pires da Silva
}

\section{SUMMARY}

The changes on soil properties due to orange cultivation were evaluated in this study. The experiment was carried out at Cambuhy orange located in Matão - SP. Two areas were selected: (i) a native forest, (ii) an orange plantation that has been established for eighteen years. Ten sampling sites were randomly selected in each area. Soil samples were taken at two positions: below the tree and in the interrow, at two depth: 0-20 and 20-40 cm. The samples were analyzed for $\mathrm{pH}$, base saturation percentage, $\mathrm{P}$ content, cation exchange capacity, organic matter, bulk density and microbial activity. Orange cultivation caused a decreased in $\mathrm{pH}$, base saturation percentage, organic matter, cation exchange capacity and microbial activity. In the other hand there was an increased in $\mathrm{P}$ content and bulk density which was the most affected soil property. 


\section{INTRODUÇÃO}

A citricultura constitui o mais importante grupo da fruticultura mundial (FAO, 1995). Neste contexto, o Brasil ocupa o primeiro lugar tanto na produção de laranjas como na industrialização e exportação de seu suco concentrado, o que tem proporcionado ao país uma receita anual de, aproximadamente, US\$ 1 bilhão, correspondentes a 1 milhão de toneladas de suco concentrado vendidas no mercado internacional.

O Estado de São Paulo é responsável por cerca de $80 \%$ da produção nacional de laranja e de $95 \%$ da produção de suco concentrado. As estimativas são de que 355 milhões de caixas foram colhidas na safra 96/97 (IEA, 1997). Apesar da extensa área citrícola, a produtividade média dos pomares paulistas é baixa, em torno de duas caixas por pé, comparada a média de 5 caixas por pé dos pomares da Flórida - EUA. O incremento na produtividade nos últimos 50 anos foi de pouco mais de 0,5 caixa por planta.

A produtividade é determinada pela interação de fatores genéticos, climáticos e do solo, sendo que as características físicas, químicas e biológicas do solo são determinantes, interagindo entre si e com as plantas. Com a retirada da vegetação natural, a implantação de culturas comerciais e a utilização de práticas agrícolas, as propriedades dos solos sofrem alterações, cuja magnitude depende de propriedades inerentes ao solo, intensidade e tipo de cultivo a que são submetidos (Scott \& Wood, 1989). 
Para avaliar as transformações no solo decorrentes do cultivo, melhores resultados poderiam ser obtidos submetendo um solo sob vegetação natural às explorações agrícolas desejadas e analisando suas propriedades periodicamente (Sanchez, 1976). O fator limitante em estudos dessa natureza é o tempo requerido para sua realização, de forma que uma outra opção para estimativa mais apropriada das tendências das alterações nas propriedades do solo é através da comparação de solos semelhantes no que se diz respeito à sua classificação e situação topográfica, sob mata natural e quando cultivados.

Há carência de trabalhos estudando as alterações nas características do solo quando a cultura de citros é introduzida, encontrando-se, na maior parte deles, somente uma avaliação das propriedades do solo submetido a diferentes tipos de manejo, não utilizando um solo sob vegetação natural como parâmetro para quantificar estes efeitos. Também há pouca informação sobre a influência da posição espacial considerada em relação à linha de plantio nas modificações nas propriedades do solo.

Para maior entendimento das alterações sobre algumas características do solo provocada pela implantação da cultura dos citros, este estudo testou a hipótese de que o cultivo de citros altera diferenciadamente as características físicas, químicas e microbiológicas do solo e que o grau de alteração entre a vegetação natural e a área cultivada depende da posição da cultura em relação à linha de plantio. Os objetivos do trabalho foram: (i) quantificar as alterações nas propriedades físicas químicas e microbiológicas do solo resultantes da implantação da cultura dos citros; (ii) avaliar se estas se alteram de forma e intensidade diferenciada e (iii) determinar se o grau de diferenciação entre a vegetação natural e a área cultivada depende da posição da cultura relativa à linha de plantio. 


\section{REVISÃO DE LITERATURA}

As matas naturais vêm sendo substituídas ao longo dos anos por culturas agrícolas. O conhecimento das mudanças que ocorrem quando um solo sob mata natural passa a ser cultivado é de grande interesse para que se tome a melhor decisão sobre o manejo a ser adotado nestes solos. A mudança na vegetação causa um desequilíbrio no ambiente, podendo provocar ou não modificações em algumas propriedades do solo, em função das condições climáticas, das espécies que são introduzidas, do manejo e do tipo de solo.

As transformações, positivas ou negativas, decorrentes da implantação da cultura, poderiam ser mais precisamente estudadas submetendo um solo sob vegetação natural ao

cultivo desejado e analisando periodicamente seus atributos químicos, físicos e microbiológicos (Sanchez, 1976). O grande fator limitante de experimentos dessa natureza é o tempo gasto para sua realização, principalmente quando se trata de culturas perenes. Desta maneira, uma opção para a estimativa mais apropriada destas alterações seria através da comparação de solos semelhantes com relação à sua classificação e posição topográfica sob mata e sob cultivo.

\subsection{Alterações nas propriedades químicas do solo}

As propriedades químicas do solo são bastante modificadas após a retirada da mata natural, principalmente na camada arável, pela adição de corretivos, adubos e pelas operações de cultivo. Estas alterações dependem de vários fatores como a cultura 
implantada e o manejo utilizado, a classe e a fertilidade inicial do solo, o comportamento físico-químico de cada nutriente e suas interações com o meio.

Algumas destas modificações foram inicialmente retratadas por Anderson \& Browning (1949), que observaram que o cultivo aumentou o $\mathrm{pH}$ do solo, reduziu os teores de potássio e que o fósforo não apresentou mudanças significativas. Aumentos nos valores de $\mathrm{pH}$ também foram descritos por Sanchez et al. (1983) em solo cultivado por oito anos e por Golding \& Lavkulich (1988), que demonstraram também que os teores de cátions foram altamente dependentes da fertilidade inicial, apresentando uma relação inversa. Lepsch et al. (1994) encontraram situação semelhante na qual, sob cultivo, os solos originalmente de alta fertilidade, sofreram reduções nos teores de cátions básicos e, ao contrário, os de baixa fertilidade foram enriquecidos.

Em áreas de pastagem, Corrêa e Reichardt (1991) verificaram que o sistema de preparo do solo para a implantação de pastagem melhorou a fertilidade do solo em relação à floresta; no entanto, devido ao manejo inadequado, a cultura foi afetada pelas deficiências de fósforo e nitrogênio no solo. Os resultados obtidos por Moraes et al. (1996) em estudos do efeito da retirada da mata e instalação de pastagem em um podzólico vermelho-amarelo na Amazônia, demonstraram que houve um aumento de $\mathrm{pH}$ e de cátions nos primeiros cinco anos de cultivo. A remoção da floresta e o estabelecimento da pastagem estaria associada a uma mudança nos teores de matéria orgânica do solo, o que resultou em um aumento no conteúdo de carbono do solo da ordem de 17 a $20 \%$.

Borges \& Kiehl (1996) constataram que a substituição da mata pelas culturas de banana, manga ou mandioca reduziu o estoque de carbono do solo, o que não foi observado para a cultura dos citros. Os cultivos não afetaram os teores totais de ácidos fúlvicos, mas reduziram os de ácido fúlvicos livres. Os autores relataram que os cultivos de banana e citros elevaram os teores de cálcio, magnésio, fósforo e zinco do solo, principalmente nos horizontes superficiais, enquanto os de sulfato aumentaram em profundidade (Borges \& Kiehl, 1997). 
Alguns estudos mostraram que a implantação da cultura do eucalipto provoca um aumento da acidez do solo e do teor de alumínio trocável, ao mesmo tempo que diminui os teores de nutrientes, principalmente de cálcio, magnésio e potássio trocáveis, na camada 0 a $20 \mathrm{~cm}$ (Lepsch, 1980; Fialho et al., 1991)

Uma diminuição no pH do solo também foi constatada em solos arenosos por Aina (1979), além de o cultivo também ter ocasionado menor capacidade de troca catiônica (CTC) e teores mais baixos de cálcio e magnésio trocáveis. Chan et al. (1992) verificaram situação semelhante, em que solos cultivados por dez anos tiveram sua CTC diminuída em 15,2\% quando comparados com solos adjacentes sob mata. O mesmo também ocorreu com os cátions trocáveis cálcio e magnésio.

O cultivo, em muitos dos solos, provocou um aumento da CTC sugerindo que este aumento, apesar do decréscimo da matéria orgânica, resultou da adição de calcário e fósforo, que provavelmente contribuíram para o aumento das cargas variáveis, ou ainda devido a modificações na qualidade físico-química dos produtos da decomposição da matéria orgânica nestas condições.

Quando se trata de solos tropicais, deve-se ressaltar a importância da contribuição da matéria orgânica para a CTC do solo, além de sua participação como fonte de nutrientes e em atributos físicos do solo.

A tendência geral, nos trópicos úmidos, é de um decréscimo nos teores de matéria orgânica do solo após a retirada da mata nativa, mas é importante ressaltar que em algumas condições o cultivo de determinadas plantas pode aumentar os teores de carbono no solo. Por exemplo, Miller et al. (1982) demonstraram que o cultivo do solo promoveu uma redução de aproximadamente $75 \%$ da matéria orgânica do solo. Num latossolo amarelo da Amazônia, Santos \& Grisi (1981) estimaram uma perda de até 50\% no primeiro ano de cultivo e $30 \%$ no segundo ano, após a queimada.

Grande parte dos estudos sobre o esgotamento da matéria orgânica em solos cultivados tem sido feitos por comparação dos conteúdos de carbono, utilizando o solo sob vegetação original como padrão de comparação. Tem-se sugerido que as perdas de matéria orgânica diminuem após um fluxo inicial, podendo cessar quando o solo atinge 
um conteúdo que represente um equilíbrio em relação ao tipo de cultura que está sendo utilizada. O rápido declínio da matéria orgânica na fase inicial do cultivo se relaciona com a oxidação, como resultado do aumento da atividade microbiológica (Rovira \& Greacen, 1957). De qualquer maneira, as perdas podem continuar principalmente devido aos efeitos de vento e erosão hídrica (Chang, 1950).

O teor de matéria orgânica do solo decresce naturalmente com a profundidade, fato que justifica as maiores perdas ocorrerem na camada superficial. Machado et al. (1981) demonstraram que em um latossolo vermelho escuro distrófico houve decréscimo acentuado da quantidade de matéria orgânica do solo na camada superficial, diminuindo gradualmente com a profundidade, quando este foi comparado com a mata natural. A diminuição do teor de matéria orgânica do solo não está unicamente ligada à redução da quantidade de resíduos vegetais disponíveis para a síntese de húmus, mas também ao aumento da atividade microbiana, principalmente pela melhoria da aeração e à alternância de umedecimento e secamento do solo (Stevenson, 1982). Em estudos sobre os teores de húmus de três latossolos vermelho-amarelos do Estado da Bahia, Volkoff (1977) constatou a dependência destes em relação aos fatores climáticos, principalmente temperatura e umidade. No entanto, Roberts \& Chan (1990) sugerem que as perdas de matéria orgânica devido a estes fatores são pequenas. As perdas em superfície $(0-15 \mathrm{~cm})$ foram atribuídas à redistribuição da matéria orgânica pela inversão do solo, provocada pela aração. Monreal \& Janzen (1993) associaram a este processo, a erosão e oxidação bioquímica.

A natureza dos resíduos também tem influência na qualidade da matéria orgânica. Os resíduos mais ricos em nitrogênio são rapidamente decompostos e a velocidade de decomposição influencia não apenas o conteúdo de matéria orgânica, mas também pode favorecer a síntese de determinada fração do húmus em detrimento de outras.

As adições de matéria orgânica em solos cultivados com banana e abacaxi foram comparadas por Godefroy \& Jacquin (1975a) com as que ocorrem em solos sob floresta, verificando-se que a introdução da cultura leva a uma redução do teor de matéria 
orgânica do solo. Eles justificam que, sob floresta, a ciclagem da matéria orgânica é contínua, e a biodegradação é regular e mais lenta do que no solo cultivado, em razão da menor temperatura média do solo. Acrescenta-se que nos solos cultivados, a incidência dos raios solares e a aeração são maiores devido às constantes operações de aração e gradagem, além da erosão ser mais intensa pela menor proteção oferecida pela cultura, em relação à floresta.

Além da cultura implantada, o manejo adotado influi na variação dos teores de matéria orgânica do solo. Machado e Brum (1978), comparando o cultivo convencional com o sistema de plantio direto, observaram que este último preveniu a perda de matéria orgânica do solo, quando comparados com a mata. Atualmente, os conceitos sobre o manejo de solos visam à manutenção da qualidade do mesmo. Por exemplo, na cultura dos citros, a grade aradora é substituída por roçadora e herbicidas no controle de plantas daninhas, além da implantação de culturas intercalares, principalmente leguminosas. Este tipo de prática visa a proteção do solo contra a erosão hídrica e a melhoria ou manutenção dos teores de matéria orgânica.

O tipo de solo é uma variável importante quando se comparam as alterações provocadas pelo cultivo. Os horizontes superficiais são geralmente diferentes dos subsuperficiais, em estrutura, textura, $\mathrm{pH}$, matéria orgânica e conteúdo de nutrientes, principalmente naqueles com gradiente textural.

Analisando o impacto do cultivo em solos de materiais de origem diferentes, Schimel et al. (1985) constataram que as concentrações de carbono variaram com o material de origem e declinaram significativamente com o cultivo em todos os tipos de solo. Observaram também que as maiores perdas de carbono ocorreram em solos de textura siltosa devido a sua baixa resistência à erosão. As perdas foram menores, e por razões diferentes, nos solos arenosos e argilosos. Nos solos de textura arenosa, a distribuição uniforme do carbono com a profundidade refletiu em menores perdas, embora facilmente erodíveis, enquanto que nos de textura argilosa, a menor perda foi devida ao maior poder de retenção da matéria orgânica. O decréscimo da matéria 
orgânica foi provavelmente a mais importante modificação ocorrida nos solos cultivados analisados por Ismail et al. (1994).

\subsection{Alterações nas propriedades físicas do solo}

O ambiente físico do solo é bastante sensível ao cultivo, e uma simples capina manual pode causar uma pulverização superficial e modificar suas propriedades (Russel \& Russel, 1961). Quando a mata é retirada e os solos são cultivados intensamente, em geral, suas características físicas se deterioram (Coote \& Ramsey, 1983).

A estrutura e a densidade do solo são altamente susceptíveis às alterações provocadas pelo cultivo. As mudanças na densidade do solo podem variar consideravelmente dependendo da textura e da quantidade de matéria orgânica do solo (Curtis \& Post, 1964). A compactação resultante do tráfego de máquinas durante operações de cultivo modifica a relação entre ar e água nos solos, com reflexos sobre o crescimento e funcionamento do sistema radicular. A formação de camadas compactadas no interior do perfil reduz o volume de solo explorado pelas raízes, reduzindo a eficiência do uso de água e nutrientes. O cultivo freqüente pode aumentar a densidade do solo na camada superficial para valores entre $20 \%$ (Hajabbasi et al., 1997) e $100 \%$ acima das condições iniciais (Martel \& Deschenes, 1976). Por outro lado, Silva e Ribeiro (1992) observaram que o cultivo da cana-de-açúcar em solos de tabuleiros não provocou alterações expressivas nas características morfológicas e físicas dos solos.

Em relação às modificações na estrutura, é bem documentado que as práticas de manejo influenciam intensamente o tamanho, a distribuição e a estabilidade dos agregados do solo (Elliott, 1986; Campos et al., 1995; Da Ros et al., 1997). O diâmetro médio dos agregados será tanto menor quanto mais intensa for a movimentação do solo, provocada pelo cultivo (Aina, 1979). Em um estudo comparativo com seis solos em estado virgem e cultivado, Anderson \& Browning (1949) verificaram maior porcentagem e estabilidade de agregados nos solos virgens. O cultivo causou um marcante aumento na densidade e reduziu a porosidade de aeração. 
Vários autores concordam que uma das hipóteses para explicar estas variações é a redução na matéria orgânica do solo, que tem papel fundamental na estabilização dos agregados do solo (Allison, 1968; Tisdall \& Oades, 1982; Mbagwu \& Bazzoffi, 1988). Os resultados obtidos por Elliott (1986) demonstram que nos microagregados, tanto em solos sob pastagem como cultivados, havia teores mais baixos de carbono, nitrogênio e fósforo orgânico quando comparados com os macroagregados. Nos solos sob cultivo, principalmente nas camadas superficiais, o aumento de microagregados está relacionado à destruição da macroestrutura pelos efeitos do preparo do solo, do tráfego de máquinas e do impacto da gota de chuva na superfície do solo descoberto. A destruição da estrutura devido ao tráfego de máquinas pesadas foi observado por Silva (1981) em um latossolo amarelo do sul do Estado da Bahia. As operações de preparo do solo em geral são realizadas em condições de umidade inadequadas, o que agrava os danos causados. $\mathrm{Na}$ cultura dos citros, maior atenção deve ser dada a operação de colheita dos frutos, principalmente das variedades tardias, que coincidem com o período mais chuvoso do ano, uma vez que o tráfego de tratores e caminhões pesados ocorre independentemente da umidade do solo. O uso contínuo de grade e herbicida provoca a formação de camadas compactadas no solo, o que foi demonstrado por Cintra et al. (1983) em pomares de laranja Baianinha submetidos a diferentes práticas de manejo. Os autores concluíram que o uso de contínuo de roçadora manteve ou melhorou as propriedades físicas do solo.

As modificações fỉsicas e morfológicas provocadas pelo cultivo intensivo de cana-de-açúcar por 5, 15 e 25 anos foram estudadas por Silva \& Ribeiro (1992) tendo sido constatado que os atributos morfológicos do solo foram modificados apenas na superficie. Houve uma incorporação do horizonte orgânico de $4 \mathrm{~cm}$ de espessura, presente no solo virgem, ao A subjacente formando o horizonte Ap. Ao contrário do que se tem observado na literatura, houve uma tendência ao melhor desenvolvimento da estrutura no solo cultivado, provavelmente devido ao abundante sistema radicular da cultura. Situação parecida foi encontrada por Cintra \& Cunha (1987) quando compararam propriedades físicas de um solo sob mata e sob a cultura do abacaxi. 
Constataram que os benefícios proporcionados pela adição de matéria orgânica compensaram os possíveis problemas decorrentes do tempo de uso e do manejo inadequado do solo. Cabe ressaltar que a quantidade de material orgânico restituído ao solo pela cultura do abacaxizeiro é da ordem de 10 a $12 \mathrm{t} \mathrm{ha}^{-1} \mathrm{ano}^{-1}$ de matéria seca, conforme Godefroy \& Jacquin (1975a) embora os autores tenham verificado que a estabilidade estrutural e o índice de permeabilidade no solo sob mata foi maior do que os cultivados com abacaxi e banana, em razão da produção contínua de material orgânico.

As relações solo-água também sofrem os efeitos do cultivo, principalmente nos solos no quais o papel da textura toma-se menos importante que o da estrutura, como é o caso dos latossolos fortemente estruturados, cuja perda de água não pode ser prevista pela textura (Sharma \& Uehara, 1968). Em latossolos com a porcentagem de argila maior que $60 \%$ e microagregados altamente estáveis, as curvas de retenção assemelhamse às de solos de textura arenosa (Sherman \& Alexander, 1959). Em solos arenosos, a água disponível aumenta com o acréscimo de matéria orgânica (Jamison, 1953; Salter et al., 1966); no entanto, naqueles com textura argilosa, a influência da textura sobre a água disponível é maior que a da matéria orgânica (Jamison \& Kroth, 1958). Em solos cultivados, Hill (1959) constatou uma maior quantidade de água disponível que os similares sob mata nativa. Resultados semelhantes foram obtidos por Jamison (1956), sugerindo que as operações de aração e o cultivo podem aumentar a água disponível por diminuírem a quantidade de matéria orgânica que está fortemente correlacionada com o conteúdo de água a 1,5 $\mathrm{MPa}$, indicando que com o aumento do carbono, a água é retida sob uma forma indisponível. Silva \& Ribeiro (1992) verificaram um aumento na água disponível, principalmente nos solos cultivados há mais de quinze anos. Por outro lado, Bauer \& Black (1994) não detectaram alterações na água disponível pelo decréscimo da matéria orgânica em solos de textura arenosa.

Constata-se na literatura que as alterações nas propriedades físicas do solo causadas pela implantação do cultivo, após a retirada da mata, ocorrem de forma e intensidade diferentes, dependendo do tipo de solo e da cultura implantada. 


\subsection{Alterações na atividade microbiana do solo}

A atividade dos microrganismos solos está intimamente relacionada com sua gênese, fertilidade e estrutura, determinados pelos processos de redução, oxidação, produção de enzimas e liberação de produtos metabólicos que provocam modificações importantes nas propriedades do solo e na produtividade das culturas.

A substituição da vegetação natural pelas culturas comerciais, assim como as práticas de manejo adotadas para cada uma delas, afetam as propriedades do solo levando a um desequilíbrio na atividade microbiológica, alterando a decomposição do material orgânico do solo e a mineralização dos nutrientes, o que é extremamente importante em solos bastante intemperizados como os brasileiros.

Vários fatores alteram diretamente a atividade microbiana, podendo ser destacado o conteúdo de água no solo, o fluxo de $\mathrm{CO}_{2}$ e $\mathrm{O}_{2}$, a temperatura, luz, e $\mathrm{pH}$ do solo.

A quantificação da atividade microbiana é, geralmente, medida pela liberação de $\mathrm{CO}_{2}$ proveniente da atividade respiratória dos microorganismos, a qual indica a biomassa microbiana deste solo, fornecendo informações sobre os possíveis efeitos das diferentes culturas e sistemas de manejo. Fonseca (1984) verificou maior quantidade de microrganismos (bactérias, fungos e actinomicetos) no solo sob eucalipto, na camada de $0-5 \mathrm{~cm}$, do que em solos sob mata natural e pastagem, relacionando estas variações às mudanças químicas e físicas do solo proporcionadas pelas diferentes vegetações. No entanto, Fialho et al. (1991) não constataram diferença significativa na atividade biológica do solos sob eucalipto, mata e pastagem, na camada de $0-20 \mathrm{~cm}$. Os autores concluíram que a microbiota não teve a sua atividade limitada pela matéria orgânica disponível. A menor atividade biológica em amostras das camadas de $2-4 \mathrm{~cm}$ sob pastagem e de $2-4$ e $4-6 \mathrm{~cm}$ sob eucalipto foi relacionada à existência de substâncias mais resistentes à decomposição microbiológica. 
Em latossolo amarelo da Amazônia, Santos \& Grisi (1981) verificaram menor atividade dos microrganismos no solo sob floresta primária. Também constataram maior taxa de respiração dos microrganismos na área de capoeira desenvolvida após derrubada e queima da floresta primária do que na área de capoeira desenvolvida após a derrubada sem a queima da floresta primária. Acreditam que a queima tende a exercer, nos primeiros anos, uma ação benéfica sobre a atividade dos microrganismos do solo, provavelmente devido ao aumento da quantidade de alguns nutrientes, bem como à insolubilização de alumínio. Resultados semelhantes foram obtidos no sul da Bahia, por Grisi \& Santos (1978).

Um aumento da ordem de $87 \%$ no número de bactérias e actinomicetos no solo que sofreu queima leve, em relação ao que não sofreu queima, na camada de $0-20 \mathrm{~cm}$ foi verificado por Silva (1981). Provavelmente este fato ocorreu em razão do fornecimento de nutrientes, devendo-se levar em conta também que o aumento da temperatura do solo não atingiu nível prejudicial aos microrganismos.

O manejo do solo e as práticas culturais atuam indiretamente sobre a atividade microbiana devido à sua influência sobre as propriedades do solo. A temperatura do solo sofre variações diárias e sazonais com marcada influência nos horizontes superficiais, portanto, nas regiões de maior atividade microbiana. Desta maneira, várias pesquisas têm demonstrado a existência de uma estreita correlação entre atividade biológica, medida pela respiração, e a temperatura do solo (Tsai et al., 1992). A acidez do solo tem sido considerada uma das propriedades químicas que mais influencia a atividade biológica (Lopes \& Cox, 1977; Selbach, 1989). O efeito da acidez está também associado à sua influência na disponibilidade de nutrientes (Selbach, 1989), e seu principal efeito está na concentração de íons hidrogênio, na deficiência de cálcio, fósforo e molibdênio e quantidades excessivas de alumínio e manganês. A inibição no crescimento microbiano, em valores de $\mathrm{pH}$ considerados desfavoráveis, resulta não só do efeito direto da elevada concentração de $\mathrm{H}^{+}$ou $\mathrm{OH}^{-}$, mas também da influência indireta do $\mathrm{pH}$ na penetração de compostos tóxicos nas células microbianas (Tsai et al., 1992). Alguns trabalhos têm 
demonstrado aumento na atividade biológica e na decomposição da matéria orgânica após a correção do solo (Salonius, 1972; Lopes \& Cox, 1977).

A implantação de culturas comerciais leva ao uso de defensivos agrícolas ou agrotóxicos, substâncias químicas destinadas ao controle de pragas e doenças, que não estavam originalmente presentes. Estas substâncias atingem o solo através de sua aplicação diretamente na superfície, pelo tratamento de sementes, controle de fungos de solo ou quando da eliminação de ervas daninhas por herbicidas. Estes compostos podem ainda atingir o solo de forma indireta pela pulverização da parte aérea das plantas. Embora alguns sejam altamente específicos, é pouco provável que eles não afetem outros organismos além daqueles ao qual se destinam. A presença dos agrotóxicos no solo influencia os processos microbiológicos em geral, como por exemplo as transformações do nitrogênio. 


\section{MATERIAL E MÉTODOS}

\subsection{Caracterização da área}

Este estudo foi conduzido em uma área pertencente à Fazenda Cambuhy (Cambuhy Agrícola Ltda.), situada entre as coordenadas geográficas $21^{\circ} 38^{\prime}$ sul e $48^{\circ} 32^{\prime}$ oeste, próxima ao município de Matão, região central do Estado de São Paulo. Cerca de 3546 ha, aproximadamente $25 \%$ da área da fazenda, encontram-se cobertos por formações florestais, representadas por 8 remanescentes e um reflorestamento. A área agricultável destina-se à citricultura, cafeicultura, produção de grãos, heveicultura e pastagens. Atualmente, as áreas de pasto e cultura anuais estão cedendo lugar ao plantio de citros. A vegetação nativa é classificada como floresta latifoliada semicaducifólia ou mata de planalto (Leitão-Filho, 1982).

Segundo a classificação de Köppen, o clima da região é do tipo Cwa: mesotérmico ou subtropical úmido, de inverno seco, com total de chuvas no mês mais seco inferior a $30 \mathrm{~mm}$, temperatura média do mês mais frio inferior a $18^{\circ} \mathrm{C}$ e a média do mês mais quente entre 23 e $24^{\circ} \mathrm{C}$. A região apresenta um índice pluviométrico variável entre 1100 e $1400 \mathrm{~mm}$. A estação seca ocorre entre os meses de maio e setembro sendo julho o mês mais seco do ano.

O município de Matão localiza-se sobre a Província geomorfológica do Planalto Ocidental, que ocupa um área de cerca de 50\% do Estado de São Paulo. Esta Província está inserida na Bacia do Paraná, e é formada por uma extensa plataforma estrutural bastante suavizada, com leve caimento para oeste e nivelada em cotas próximas a $500 \mathrm{~m}$. 
O relevo é do tipo colinoso, onde predominam declividades de até $15 \%$ e amplitudes locais inferiores a $100 \mathrm{~m}$, ocorrendo colinas médias (Almeida et al., 1981). Os solos são desenvolvidos sobre arenitos do grupo Bauru, podendo ter cimento calcário. Os solos originários deste material são férteis e com saturação por bases elevada. Porém, quando o cimento que consolida os grãos de quartzo não é o calcário, os solos são mais ácidos, menos férteis e com saturação por bases baixa.

De acordo com a Comissão de Solos (1960), o tipo de solo predominante na região é o Pln: Solos Podzolizados de Lins e Marília, Variação Lins, que correspondem, no sistema de classificação atual (Camargo et al., 1987; Embrapa, 1981), ao solo Podzólico Vermelho Amarelo Tb (Ultisol) textura arenosa/média, fase relevo suave ondulado, cujo principal fator limitante é a susceptibilidade à erosão.

\subsection{Seleção e descrição das glebas}

Para a comparação entre áreas cultivadas e sob vegetação nativa, selecionaram-se locais próximos (Figura 1), com ecossistema natural preservado e com agroecossistema citros, estabelecidos em uma mesma classe de solo e pertencentes a mesma classe textural. O Mapa semi-detalhado de solos Fazendas do Cambuhy - Matão - SP em escala 1:20.000, elaborado por Demattê (1980), indica que nas áreas selecionadas o solo é do tipo Podzólico Vermelho Amarelo, com o horizonte Bt localizado a uma profundidade superior a $40 \mathrm{~cm}$. Segundo Demattê (1980) o Podzólico Vermelho Amarelo é um dos solos de maior ocorrência na fazenda, sendo relativamente profundo, com camadas superficiais escurecidas pela matéria orgânica e a camada inferior com cores vermelho-amareladas, originadas do arenito Bauru.

A gleba sob mata encontra-se na Mata da Represa do Carvão que é uma das 8 remanescentes florestais da fazenda (Figura 2), cuja maior parte encontra-se averbada em cartório, constituindo a Reserva Legal da Fazenda Cambuhy. Trata-se de uma floresta latifoliada semicaducifólia ou mata de planalto (Leitão Filho, 1982). 


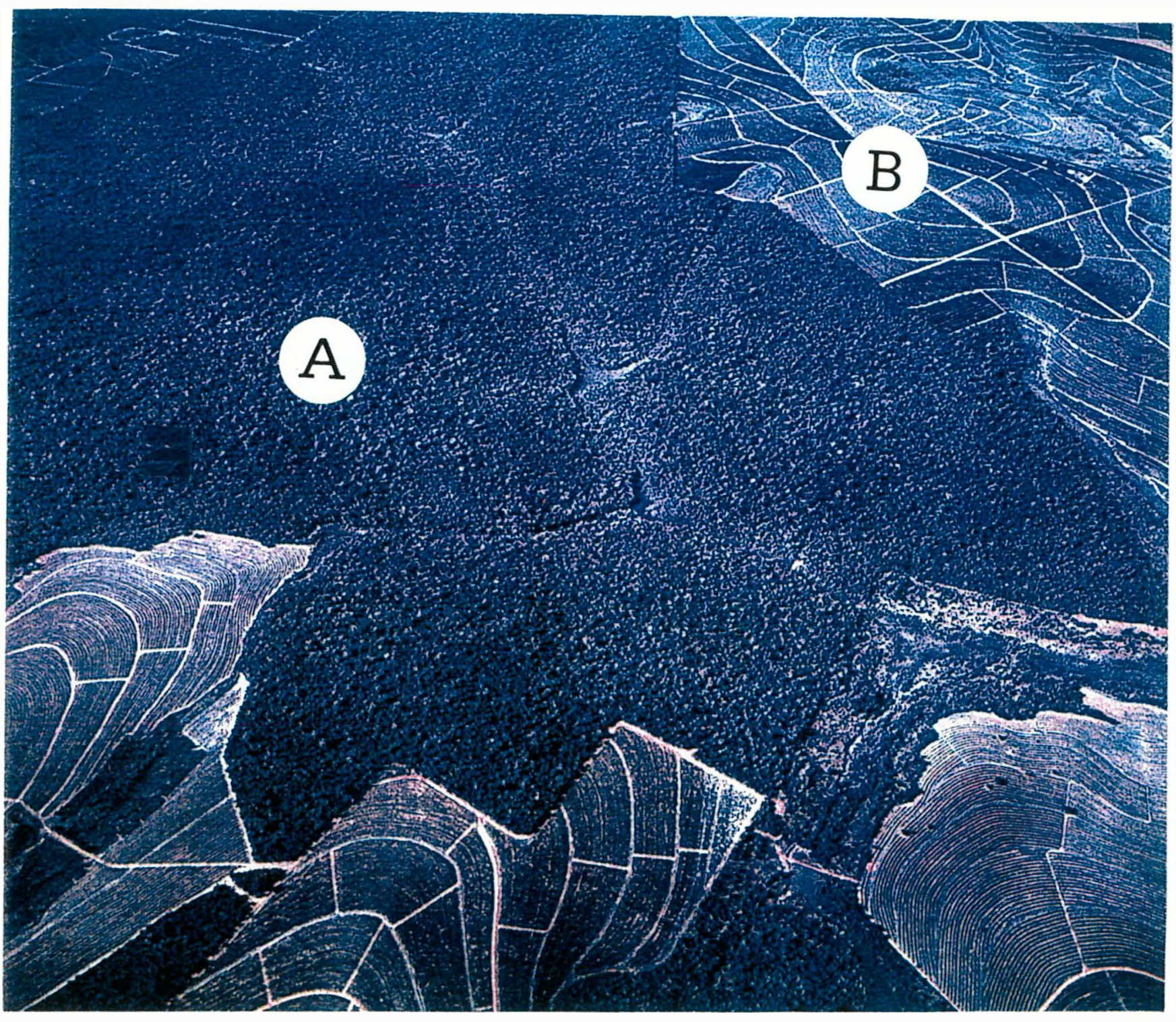

Figura 1 - Vista aérea geral do local onde foram selecionadas as áreas amostradas (A - mata natural, B - cultivo de citros). 
A área cultivada corresponde a quadra 19, talhão 147 da Cambuhy Agrícola Ltda. Esta área encontra-se sob um pomar de laranjeira 'Natal' (Citrus sinensis (L.) Osbeck), sobre porta enxerto limoeiro 'Cravo' (Citrus limonia Osbeck), com dezoito anos. O talhão ocupa 14,60 ha com 3046 plantas no espaçamento $8 \mathrm{~m} \times 6 \mathrm{~m}$.

As recomendações de adubação e calagem são feitas de acordo com resultados de experimentos desenvolvidos na própria fazenda, com base em análises de solo realizadas anualmente.

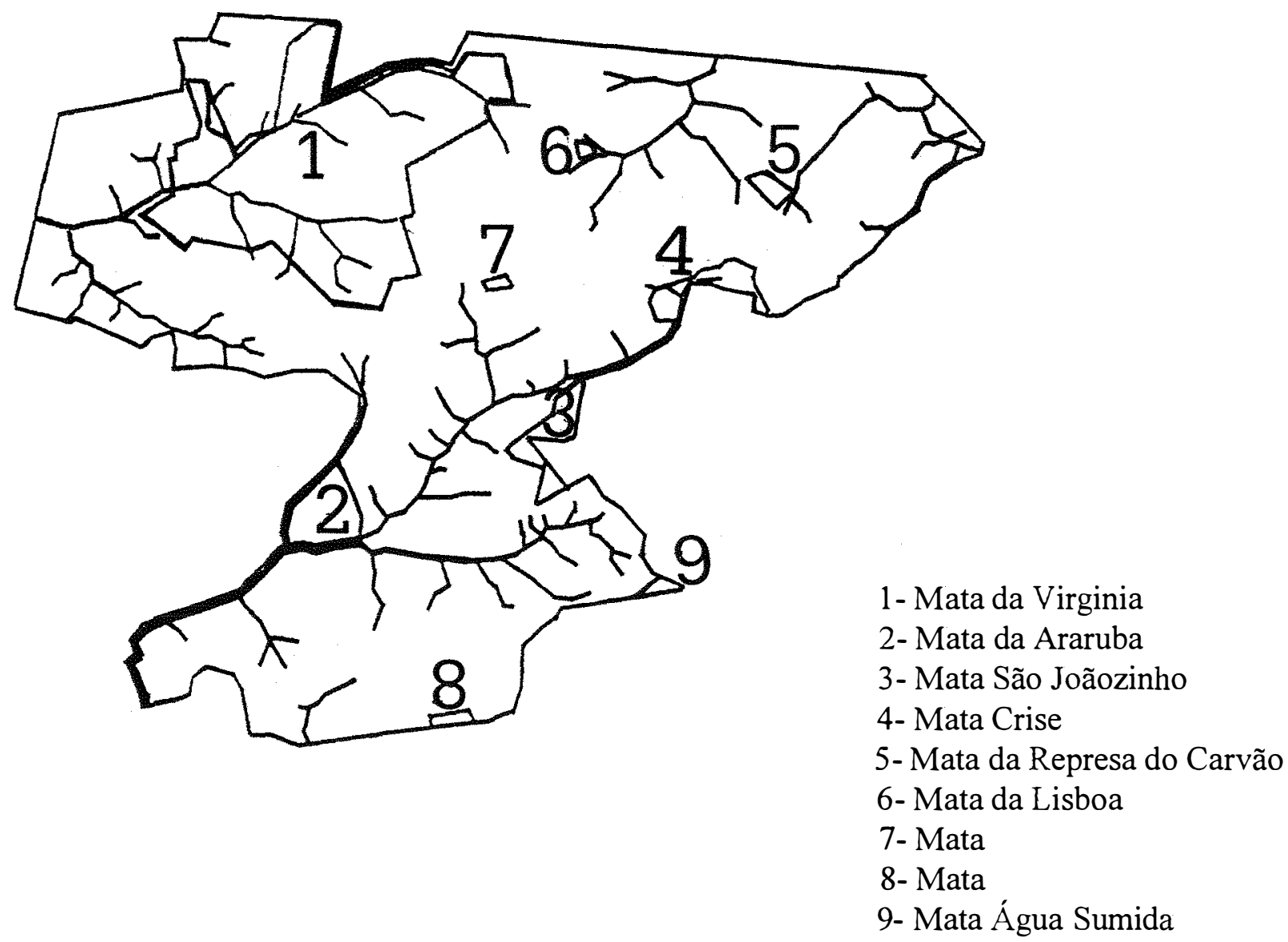

Figura 2 - Fazenda Cambuhy, com localização das áreas de vegetação nativa. 


\subsection{Amostragem}

A amostragem foi feita distribuindo-se aleatoriamente dez pontos na mata, dez pontos na projeção da copa e dez pontos na entrelinha da cultura, como esquematizado na Figura 3. Em cada ponto foram retiradas 2 amostras: uma deformada com cerca de $250 \mathrm{~g}$ de terra e outra amostra indeformada com anel metálico $(5 \mathrm{~cm}$ de diâmetro e $5 \mathrm{~cm}$ de altura) nas profundidades de 0-20 e 20-40 cm. Cada ponto constituiu uma repetição.

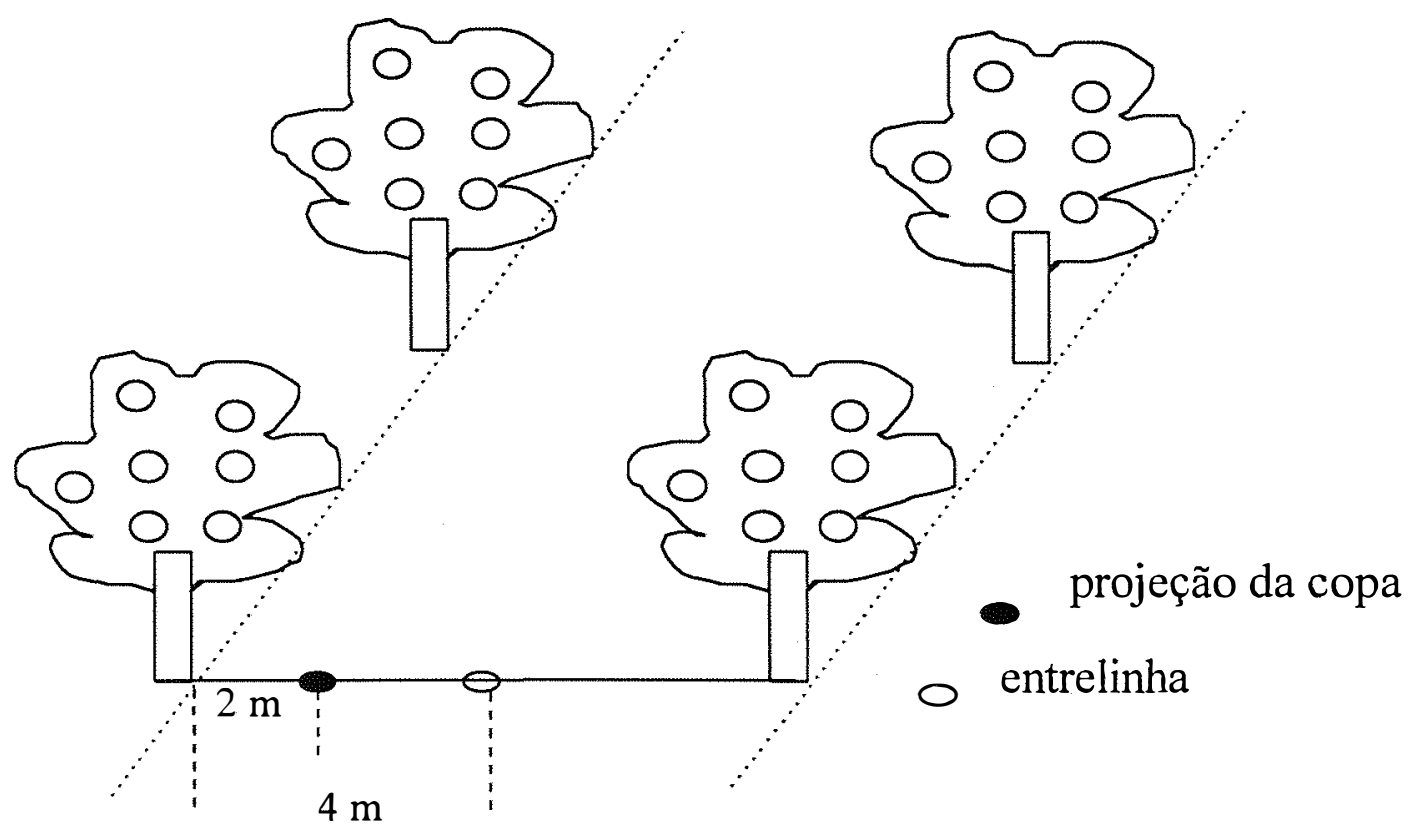

Figura 3 - Local onde foram retiradas as amostras na área cultivada.

\subsection{Determinações e procedimentos analíticos}

\subsubsection{Densidade do solo (Ds)}

Foi determinada nas amostras indeformadas pelo método do anel volumétrico (Blake \& Hartge, 1986). 


\subsubsection{Análises químicas do solo}

As análises químicas foram realizadas em amostras de solo secas ao ar e passadas por peneira de $2 \mathrm{~mm}$ de diâmetro de malha. Foram realizadas as seguintes determinações:

- pH do solo: determinado em solução centimolar de cloreto de cálcio de acordo com Raij \& Quaggio (1983);

- Fósforo "disponível": extraído com resina trocadora de íons e determinado pelo método do complexo fosfomolíbdico empregando-se ácido ascórbico como redutor (Raij \& Quaggio, 1983).

- CTC e saturação por bases (V\%) foram calculadas segundo Camargo et al. (1986);

- Matéria orgânica: através de oxidação com solução de dicromato de potássio em presença de ácido sulfúrico, utilizando como catalisador da oxirredução o calor desprendido na diluição do ácido sulfúrico e titulação do excesso de dicromato com sulfato ferroso amoniacal (Camargo et al., 1986).

\subsection{Análise microbiológica}

Para determinar a atividade da microflora heterotrófica do solo foi utilizado o método da radiorespirometria que baseia-se na adição de um ${ }^{14} \mathrm{C}$-substrato e sua transformação em ${ }^{14} \mathrm{CO}_{2}$ pelos organismos heterotróficos do solo (Freitas et al., 1979). A quantidade de ${ }^{14} \mathrm{C}$-substrato consumida é proporcional à atividade da microflora heterotrófica do solo. 
As amostras de solo foram equilibradas e mantidas a $70 \%$ da capacidade de campo por uma semana visando reativar a microflora. A determinação foi feita utilizando-se 2,0g de solo de cada amostra, colocadas em Erlenmeyers de $75 \mathrm{ml}$. Sobre este solo foi adicionado $0,5 \mathrm{ml}$ de uma solução de glicose- $-{ }^{14} \mathrm{C} \mu \mathrm{mol} \mathrm{ml}{ }^{-1}$ com atividade de $0,05 \mu \mathrm{Ci} \mathrm{ml}^{-1}$. No interior dos Erlenmeyers, foram colocadas cubetas presas na tampa contendo 0,5 ml de $\mathrm{KOH} \mathrm{0,2} \mathrm{mol} \mathrm{l}^{-1}$ para absorver o $\mathrm{CO}_{2}$ resultante da metabolização da glicose radiomarcada, e para aumentar a superfície de contato entre o $\mathrm{CO}_{2}$ e a solução de $\mathrm{KOH}$ utilizou-se pequenas tiras de papel de filtro (Figura 4).

Após fechados, os frascos foram incubados por 1 hora a $25^{\circ} \mathrm{C}$. No final deste período, a reação foi paralisada com a adição de $2,0 \mathrm{ml} \mathrm{de} \mathrm{HCl} 1 \mathrm{~mol} \mathrm{l}^{-1}$ sobre o solo, e, o papel de filtro juntamente com a feniletilamina foram transferidos para frascos de cintilação contendo $10 \mathrm{ml}$ de solução cintiladora. O padrão foi feito com $0,5 \mathrm{ml}$ da solução de glicose $-{ }^{14} \mathrm{C}$, transferida para frascos de cintilação. As contagens do ${ }^{14} \mathrm{C}$ das amostras e do padrão foram realizadas em um cintilador líquido BECKMAN L5-230, pertencente à Seção de Radioisótopos do Centro de Energia Nuclear na Agricultura (CENA).

A quantidade de glicose consumida pelos microrganismos do solo é proporcional à contagem por minuto $(\mathrm{cpm})$, dada pelo cintilador líquido, através da leitura do isótopo radioativo $\left({ }^{14} \mathrm{C}\right)$. É expressa em $\mu \mathrm{mol}$ de glicose $\mathrm{g}^{-1}$ solo hora ${ }^{-1}$ e foi obtida através da seguinte equação:

na qual,

$$
X=\left(a / a_{0}\right) \cdot(C / M) \cdot(V / T)
$$

$\mathrm{X}=$ quantidade de glicose consumida $\mu \mathrm{mol} \mathrm{g}^{-1} \cdot \mathrm{h}^{-1} ;$

$\mathrm{a}=$ contagem por minuto da amostra;

$\mathrm{a}_{0}=$ contagem por minuto do padrão;

$\mathrm{C}=$ concentração da solução de glicose ${ }^{14} \mathrm{C}\left(\mu \mathrm{mol} \mathrm{ml} l^{-1}\right)$;

$\mathrm{M}=$ massa de solo $(\mathrm{g})$;

$\mathrm{V}=$ volume de solução glicose- $-{ }^{14} \mathrm{C}(\mathrm{ml})$ adicionada ao solo e

$\mathrm{T}=$ tempo de incubação das amostras (hora). 


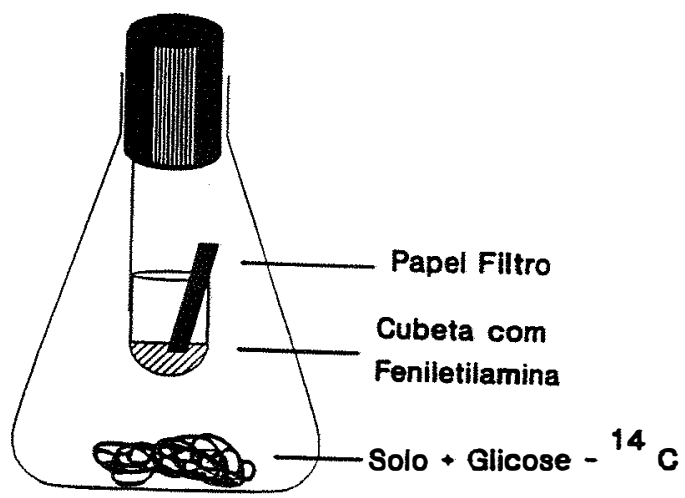

Figura 4 - Frasco rádiorespirométrico

\subsection{Análise estatística}

Os dados obtidos foram analisados usando o teste t para amostras independentes (SAS, 1991), sendo foram feitas comparações entre a mata e a posição da projeção da copa das plantas, e entre mata e entrelinha da cultura. 


\section{RESULTADOS E DISCUSSÃO}

O cultivo da laranjeira 'Natal' por dezoito anos, alterou significativamente as propriedades químicas do solo. Os valores médios do $\mathrm{pH}$ para os solos sob mata $\mathrm{e}$ cultivo, nas profundidades de 0-20 e 20-40 cm, são apresentados na Figura 5. Os resultados indicaram que houve uma acidificação do solo. A alteração do pH foi função da posição amostrada na área de cultivo, sendo que a redução do $\mathrm{pH}$ foi significativa somente quando considerada a área sob a projeção da copa das plantas. Nesta posição o pH do solo decresceu, em média, 1,66 unidade na camada superficial e 0,63 em subsuperfície em relação ao $\mathrm{pH}$ no solo sob mata nativa.

Esta redução diferenciada do $\mathrm{pH}$ do solo nas duas profundidades também foi constatada por Cerri (1986) e Lima (1995), comparando solos eutróficos cultivados com cana-de-açúcar e sob vegetação natural. Os autores concluíram que esse comportamento estava associado à diminuição dos teores de cátions trocáveis.

Neste estudo, a redução do $\mathrm{pH}$ na projeção da copa das plantas pode estar relacionada à maneira como é feita a aplicação de corretivos e fertilizantes na cultura dos citros. O calcário, utilizado como corretivo, normalmente é distribuído a lanço em área total no pomar. Entretanto, a posição das plantas sobre a área define a projeção da copa e a entrelinha as quais, no decorrer do manejo, acabam recebendo tratamento diferenciado. Em estudo realizado por Luz (1995), a aplicação de calcário a lanço resultou em doses $42,3 \%$ abaixo e $18,6 \%$ acima da quantidade recomendada na projeção da copa e na entrelinha da cultura, respectivamente. As adubações, via de regra, são aplicadas localizadamente na projeção da copa. Deste modo, os processos de acidificação do solo 
também se manifestarão diferentemente, em posições distintas dentro dos pomares, principalmente no caso do uso de adubos nitrogenados (Vitti et al.,1996).

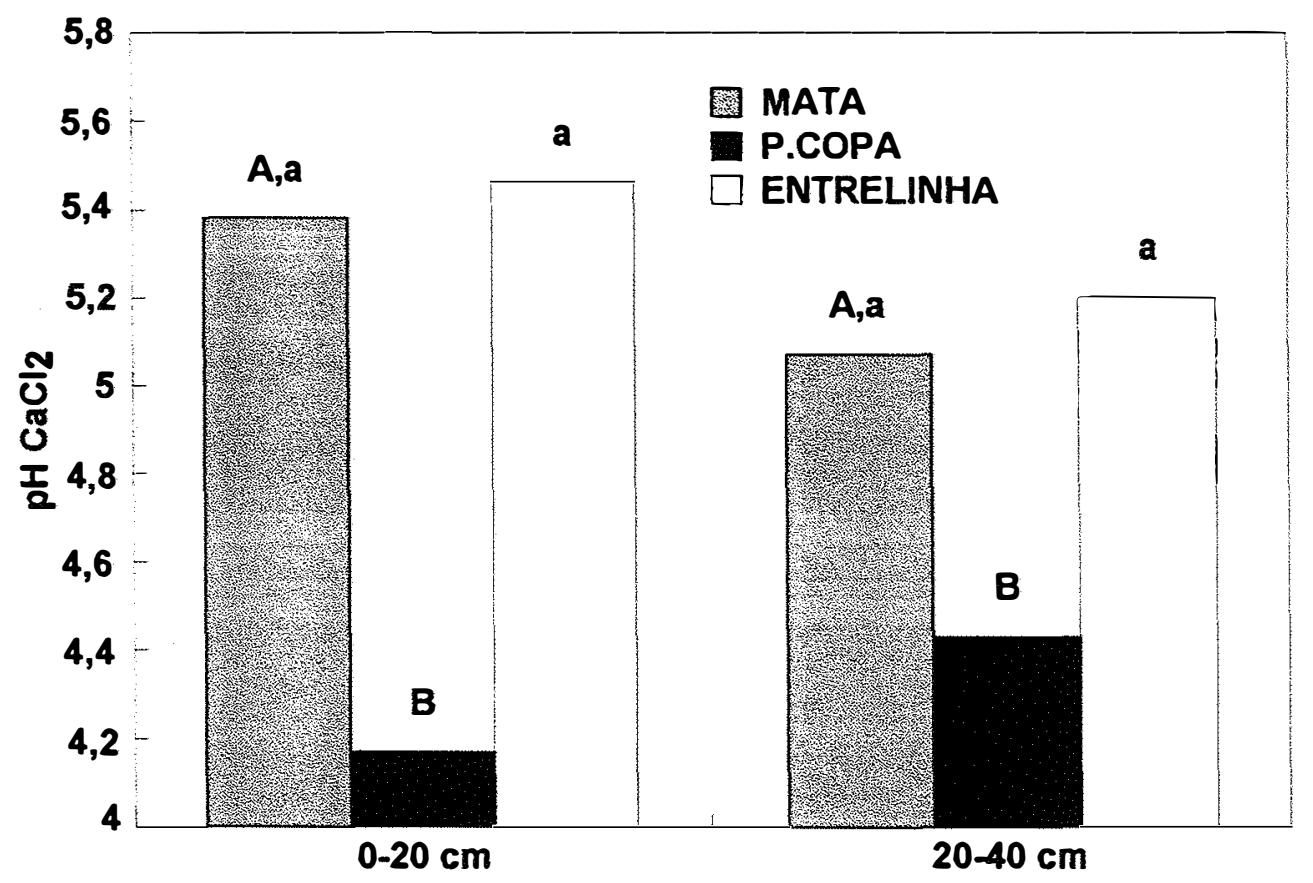

Figura 5 - Valores médios de $\mathrm{pH}$ nas profundidades $0-20$ e 20-40 cm, para os três locais considerados. As letras maiúsculas representam o resultado da comparação de médias (teste $t$ a $5 \%$ ) entre a mata e a área sob cultivo na posição da projeção da copa. As letras minúsculas representam o resultado da comparação de médias (teste t a $5 \%$ ) entre a mata e a área sob cultivo na posição da entrelinha.

A acidificação do solo em pomares de citros é decorrente do uso de fertilizantes nitrogenados, principalmente daqueles contendo $\mathrm{N}$ na forma amoniacal ou amídica, como também pelo uso de enxofre elementar para o controle de ácaros (Quaggio, 1991). O autor afirma que a acidificação do solo é quase inevitável nos pomares de citros, mas que poderia ser reduzida evitando-se o uso de fertilizantes amoniacais e do enxofre elementar para o controle de ácaros. Uma ampliação na faixa de adubação seria desejável 
evitando-se assim a acidificação localizada e intensa na projeção da copa das plantas, além de provavelmente ampliar a área de solo explorado pelas raízes.

Em relação à saturação do complexo de troca por bases (Figura 6), os resultados demonstram uma tendência de redução na mata e entrelinha e, um aumento na posição da projeção da copa das plantas com o aumento da profundidade. Na projeção da copa, os valores de V\% foram significativamente menores que os da mata e da entrelinha da cultura, tanto em superfície quanto em subsuperfície. O V\% no solo sob mata e na entrelinha da cultura estão classificados como altos, segundo limites de classes considerados no estado de São Paulo (Raij, 1991). Os valores de V\% na projeção da copa estão próximos à média encontrada em áreas cultivadas com citros no estado de São Paulo, que foram de $52,7 \%$ para a camada de $0-20 \mathrm{~cm}$ e de $47,0 \%$ para a camada de 20-40 cm, de acordo com Quaggio (1996).

Segundo as Recomendações de Adubação e Calagem para Citros, no Estado de São Paulo (Grupo Paulista, 1994) a faixa adequada de V\% encontra-se entre 60 e 70\%. Neste estudo, os valores de V\% na entrelinha são considerados adequados para a cultura, não diferindo significativamente da condição sob mata natural. Por outro lado, na projeção da copa das plantas notou-se que os valores encontrados (Figura 6) estão abaixo daqueles considerados adequados.

Em pomares de laranja 'Valência', Quaggio (1991) observou que, nas amostras de solo coletadas na projeção da copa, os valores de $\mathrm{V} \%$ foram menores do que naquelas coletadas na entrelinha da cultura. A acentuada redução em V\% na projeção da copa das plantas, em relação ao solo sob mata e a entrelinha da cultura, pode estar associada a remoção de cátions, principalmente o $\mathrm{Ca}, \mathrm{Mg}$ e $\mathrm{K}$, por absorção pelas plantas, lixiviação e erosão. Em razão das alterações diferenciadas, quando consideradas as duas posições dentro da cultura, Quaggio (1994) sugeriu que a coleta de amostras de terra para a citricultura deve ser feita em toda a faixa de adubação, considerando-se pontos de amostragem na projeção da copa e também distantes dela de 1 a $1,5 \mathrm{~m}$ em direção ao meio das ruas. 
Os resultados obtidos para o P são mostrados na Figura 7. Observaram-se diferenças significativas, entre mata e cultivo, quando foi considerado o solo sob a projeção da copa das plantas. O teor de $\mathrm{P}$ nesta posição foi seis vezes maior do que aquele do solo sob condição natural para a camada $0-20 \mathrm{~cm}$, e quatro vezes maior para a camada $20-40 \mathrm{~cm}$.

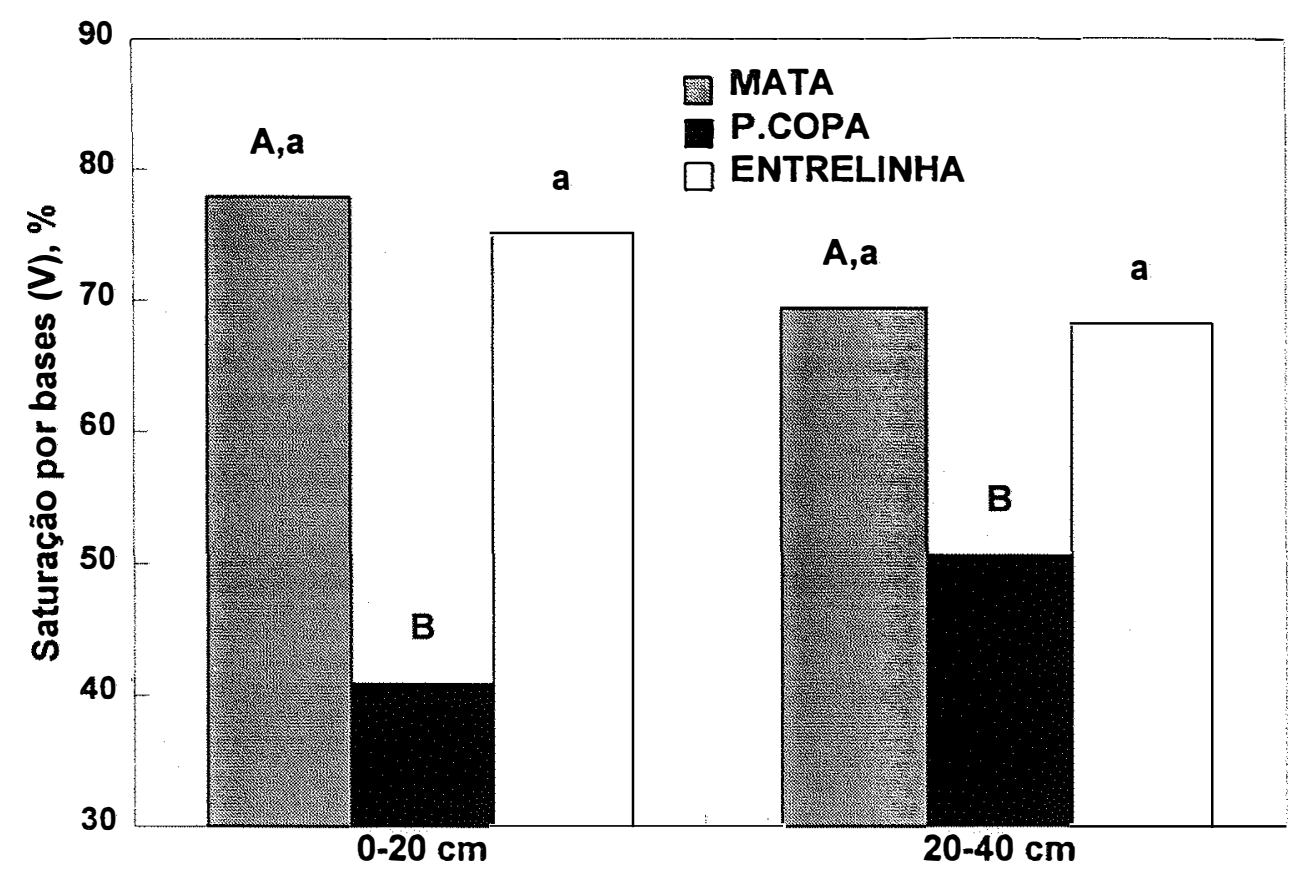

Figura 6 - Valores médios de V\% nas profundidades $0-20$ e $20-40 \mathrm{~cm}$, para os três locais considerados. As letras maiúsculas representam o resultado da comparação de médias (teste $t$ a $5 \%$ ) entre a mata e a área sob cultivo na posição da projeção da copa. As letras minúsculas representam o resultado da comparação de médias (teste t a 5\%) entre a mata e a área sob cultivo na posição da entrelinha.

Os valores elevados de P no solo na projeção da copa deveu-se, provavelmente, às quantidades deste nutriente adicionadas anualmente, via adubação, nesta posição. Podendo-se destacar, também, a baixa mobilidade deste elemento no solo, assim como a baixa solubilidade de seus compostos. Além disso, somente uma pequena quantidade de 
P é removida do solo pela colheita. Pratt et al. (1956) concluíram que as frutas retiradas de um pomar de laranja na Califórnia, em um período de vinte e oito anos, somaram somente $2 \%$ do total de P da camada 0-90 cm. Bryan (1933) cita que o teor de P no solo aumentou com a idade do pomar, aparentemente devido ao acúmulo pela aplicação ao longo dos anos.

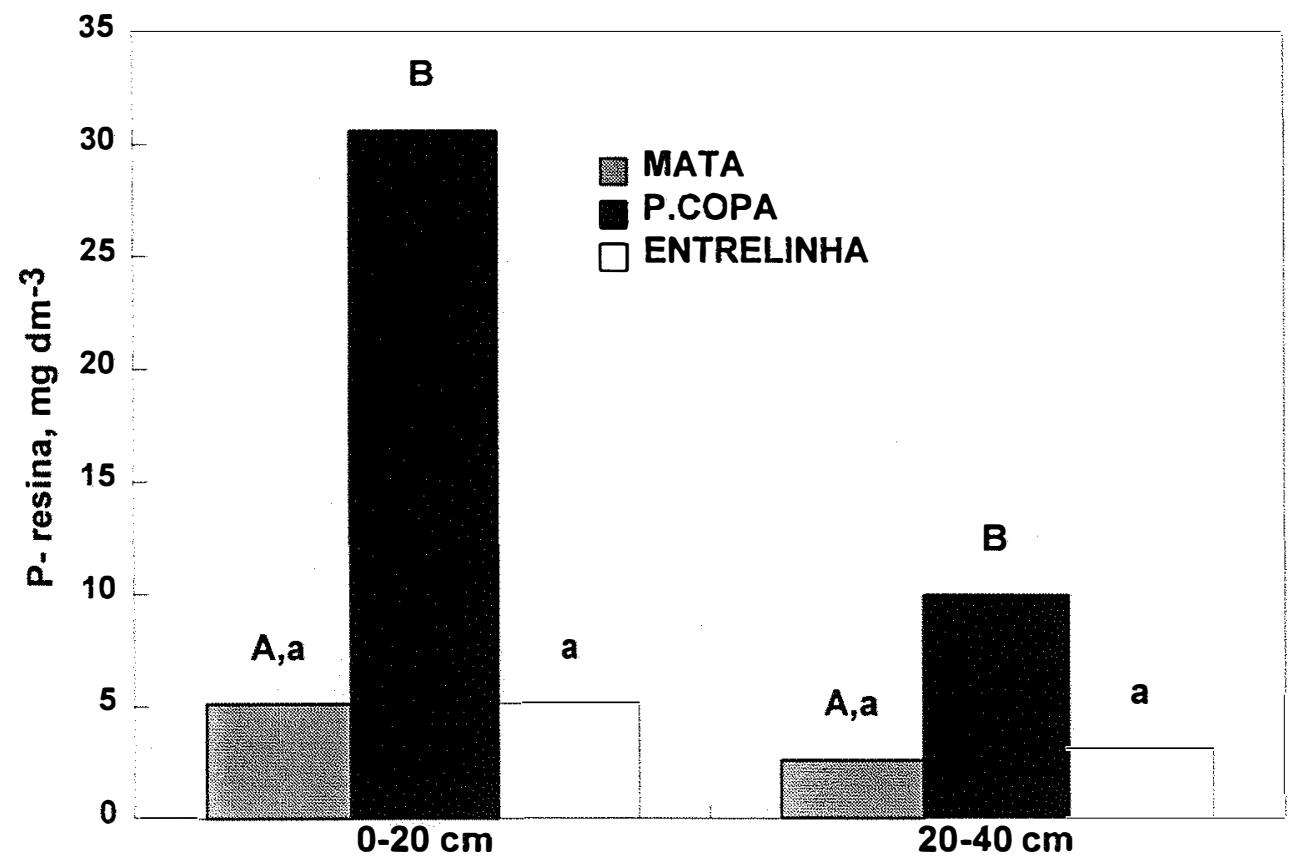

Figura 7 - Valores médios de P nas profundidades 0-20 e 20-40 cm , para os três locais considerados. As letras maiúsculas representam o resultado da comparação de médias (teste t a $5 \%$ ) entre a mata e a área sob cultivo na posição da projeção da copa. As letras minúsculas representam o resultado da comparação de médias (teste ț a 5\%) entre a mata e a área sob cultivo na posição da entrelinha.

Pesquisas demonstram que o $\mathrm{P}$ aplicado não se move para camadas inferiores. Os resultados obtidos por Borges \& Kiehl (1997) demonstram teores três vezes maior na superfície $(0-9 \mathrm{~cm})$ do que nas camadas inferiores $(38-70 \mathrm{~cm})$, em um latossolo amarelo álico cultivado com citros na Bahia. 
Segundo os padrões de fertilidade para interpretação de resultados de análise de solo para citros do Grupo Paulista de Adubação e Calagem para Citros, teores de P inferiores a $6 \mathrm{mg} \mathrm{dm}^{-3}$ são considerados muito baixos. Os resultados indicam que o solo em estudo possui baixos teores deste elemento. Os valores considerados adequados encontram-se na faixa de $13-30 \mathrm{mg} \mathrm{dm}^{-3}$.

A comparação dos teores médios de matéria orgânica são apresentados na Figura 8. Nas duas profundidades observou-se diferença significativa entre o solo sob cultivo e sob mata. O solo cultivado apresentou teores de matéria orgânica mais baixos que o solo sob mata natural, para as duas camadas consideradas, independentemente da posição da cultura.

Diversos autores concordam que nos trópicos úmidos a tendência geral é de decréscimo nos teores de matéria orgânica do solo após a retirada da mata nativa. Algumas estimativas são encontradas como, por exemplo, no trabalho de Santos e Grisi (1981), no qual foram constatadas perdas de $50 \%$ no primeiro ano de cultivo em latossolo amarelo da Amazônia. Miller et al. (1982) afirmam que a substituição da mata nativa por culturas, no sistema agrícola dos trópicos úmidos, acarretou redução de, aproximadamente, $75 \%$ na matéria orgânica do solo. Para o solo em estudo, as perdas foram, em média, de $50 \%$ para a camada superficial e de $30 \%$ para a camada subsuperficial.

As perdas foram mais acentuadas na camada superior, o que é justificável, já que o teor de matéria orgânica do solo diminuiu naturalmente com o aumento da profundidade (Figura 8). Machado et al. (1981) encontraram situação semelhante, em que as perdas foram mais acentuadas na superfície sendo reduzidas, gradualmente, com a profundidade. É possível que a redução no teor de matéria orgânica esteja associada à diminuição na restituição de material orgânico ao solo. É grande o retorno deste material na área sob mata nativa. Em florestas tropicais, alguns trabalhos têm demostrado que estas restituem ao solo anualmente de 9 a $15 \mathrm{t} \mathrm{ha}^{-1}$ de matéria seca (Cunnigham, 1963; Godefroy \& Jacquin, 1975a). 
De acordo com Stevenson (1982) a diminuição do teor de matéria orgânica no solo sob cultivo não está unicamente associada à redução da quantidade de resíduos orgânicos, sendo também causada pela melhoria da aeração do solo e a maior alternância de ciclos de umedecimento e secagem, fenômenos que podem levar ao aumento da atividade microbiana e, assim, à redução do teor de matéria orgânica do solo.

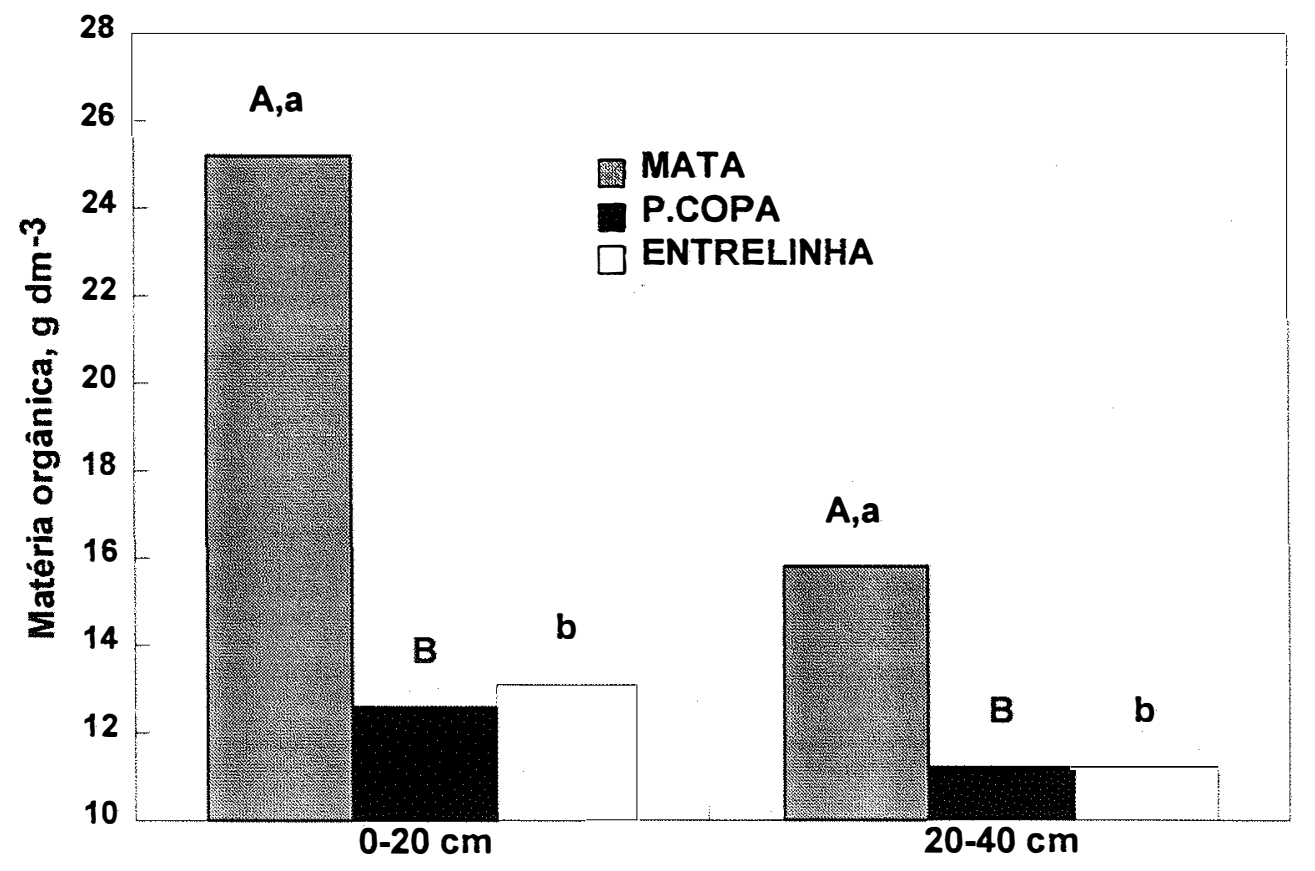

Figura 8 - Valores médios de matéria orgânica nas profundidades 0-20 e 20-40 cm , para os três locais considerados. As letras maiúsculas representam o resultado da comparação de médias (teste t a 5\%) entre a mata e a área sob cultivo na posição da projeção da copa. As letras minúsculas representam o resultado da comparação de médias (teste $t$ a $5 \%$ ) entre a mata e a área sob cultivo na posição da entrelinha.

A diferença dos teores de matéria orgânica entre a superfície e a subsuperfície foi menor no solo cultivado que no solo sob mata, podendo estar associada às perdas por erosão e pela menor proteção oferecida pela cultura em relação à floresta (Monreal \& Janzen, 1993). 
A CTC foi bastante alterada com a retirada da mata e implantação da cultura da laranja, nas duas profundidades consideradas (Figura 9). Aina (1979) e Chan et al. (1992) também observaram uma queda na CTC do solo quando a mata é substituída por culturas comerciais. A alteração na CTC do solo não ocorreu de maneira diferenciada dentro da área cultivada.

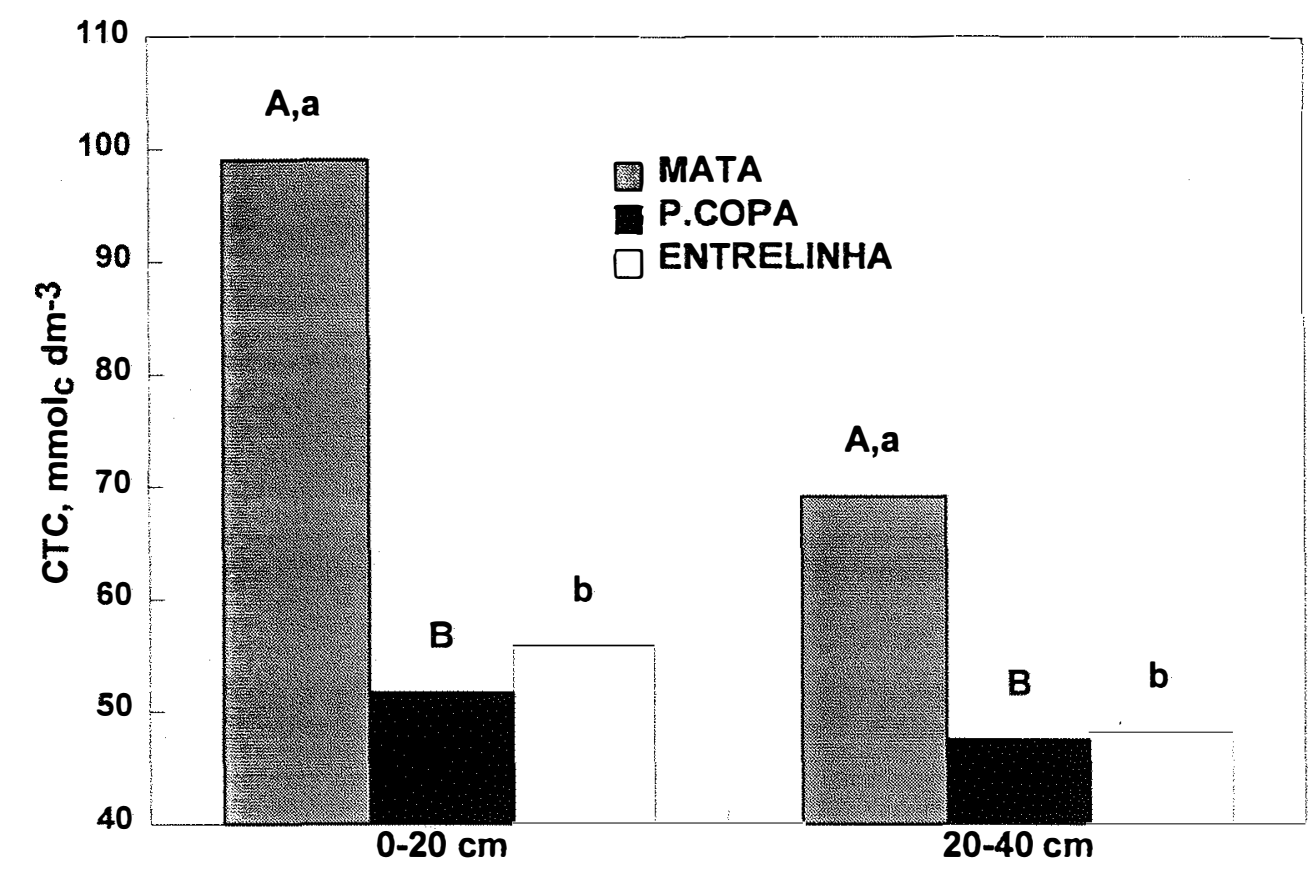

Figura 9- Valores médios de CTC nas profundidades $0-20$ e $20-40 \mathrm{~cm}$, para os três locais considerados. As letras maiúsculas representam o resultado da comparação de médias (teste a $5 \%$ ) entre a mata e a área sob cultivo na posição da projeção da copa. As letras minúsculas representam o resultado da comparação de médias (teste $\underline{\mathrm{t}}$ a $5 \%$ ) entre a mata e a área sob cultivo na posição da entrelinha.

Em se tratando de solos tropicais, deve-se ressaltar a importância da matéria orgânica para a CTC do solo, principalmente na superfície (Sanchez, 1979). Para o solo em estudo, verificou-se decréscimo linear da CTC do solo com o decréscimo da matéria orgânica $\left(\mathrm{r}^{2}=0,91, \mathrm{P}<0,001\right)$ indicando que o decréscimo no valor da CTC do solo 
cultivado foi diretamente relacionado com a perda da matéria orgânica (Figura 10), confirmando as observações de Brams (1971). O manejo da CTC é importante em muitos solos tropicais altamente intemperizados, onde a manutenção da matéria orgânica é quase sinônimo de manutenção da CTC .

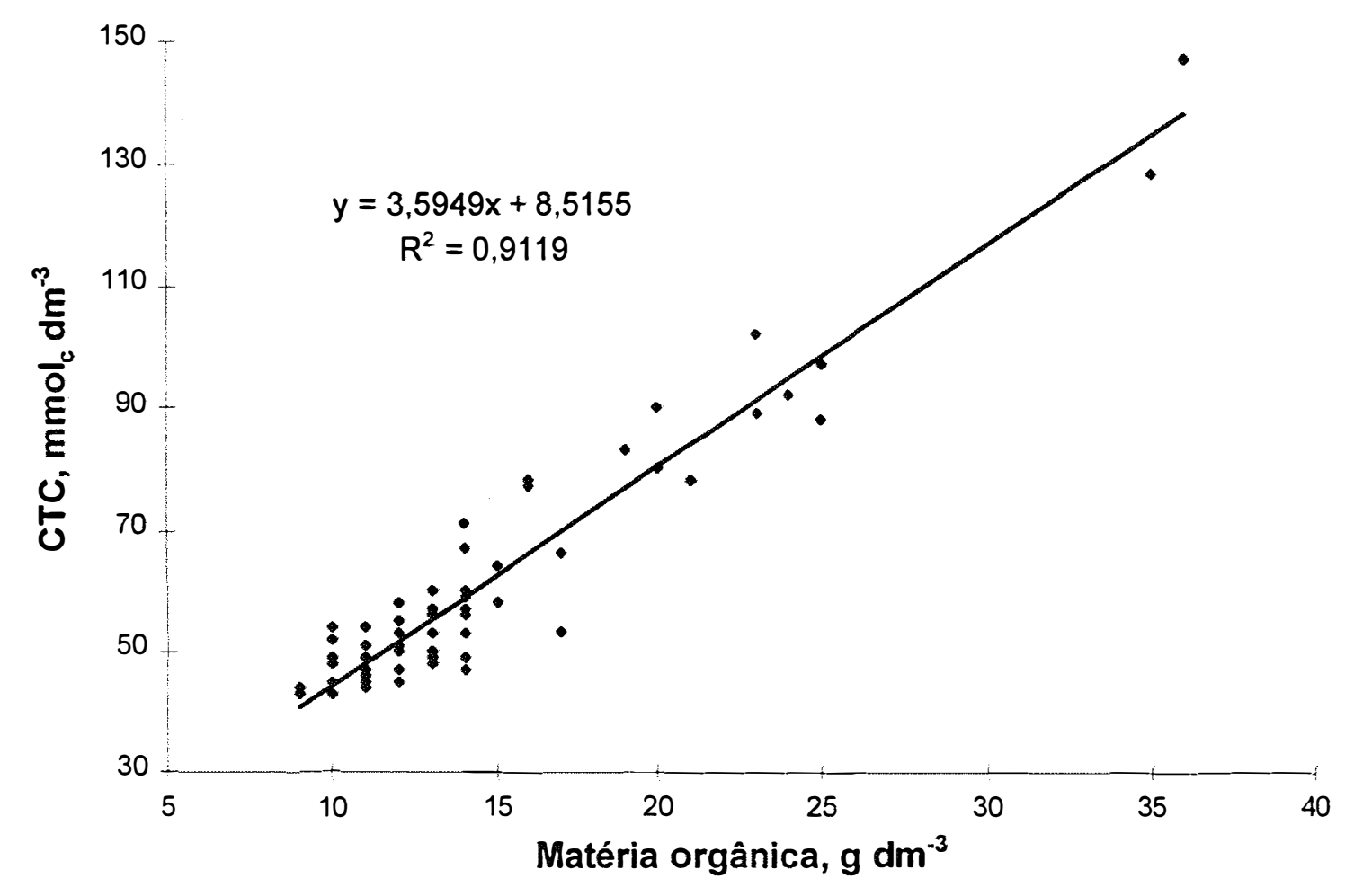

Figura 10 - Relação entre CTC e matéria orgânica no solo estudado.

O cultivo da laranjeira modificou significativamente a densidade do solo (Figura 11). Observa-se que, no solo cultivado, os valores de densidade do solo foram muito mais elevados, nas duas posições avaliadas, na área sob cultivo quando comparada com a área da mata. $\mathrm{O}$ aumento da densidade do solo com o cultivo pode estar relacionado a vários mecanismos. Dentre eles, pode-se destacar a pressão exercida pelos implementos agrícolas e pelo tráfego excessivo, como constatado por Cassel (1983), Carter (1987), Hammel (1989) e Hajabbasi et al. (1997). 


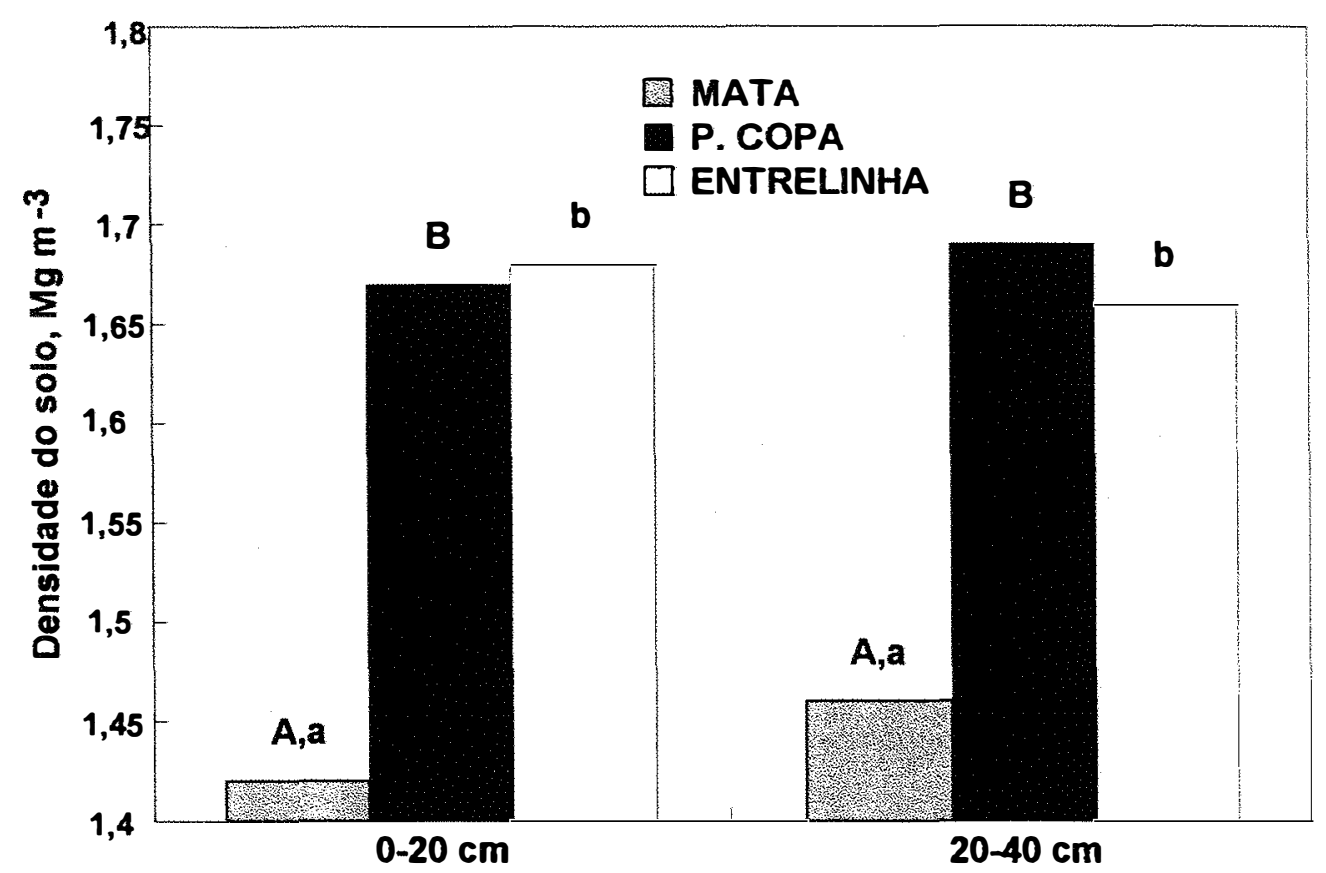

Figura 11 - Valores médios de densidade do solo nas profundidades 0-20 e 20-40 cm, para os três locais considerados. As letras maiúsculas representam o resultado da comparação de médias (teste $\mathrm{t}$ a $5 \%$ ) entre a mata e a área sob cultivo na posição da projeção da copa. As letras minúsculas representam o resultado da comparação de médias (teste t a $5 \%$ ) entre a mata e a área sob cultivo na posição da entrelinha.

O tráfego excessivo na cultura da laranja está associado ao elevado número de operações como adubações, pulverizações e controle do mato. Tersi \& Rosa (1995) citam que é comum uma freqüência em torno de 15 passadas de trator / implemento em um ano agrícola, e que estas provavelmente ocorrem numa grande variação de umidade no solo.

O controle contínuo do mato feito com herbicidas e uso de grade foi apontado por Cintra et al. (1983) como causa da formação de camadas compactadas e adensamento na superficie de um solo cultivado com laranja. De acordo com Laws \& 
Evans (1949) e Hajabbasi et al. (1997), estas condições provocam um decréscimo da macroporosidade, o que contribui para elevação nos valores da densidade do solo.

A perda de matéria orgânica ocorrida no solo sob cultivo, igualmente para projeção da copa e entrelinha, também favoreceu o aumento da densidade do solo após a implantação da cultura. Scott \& Wood (1989) obtiveram correlação significativa e negativa entre teor de matéria orgânica e densidade do solo. Esta relação inversa entre a densidade do solo e o teor de carbono pode ser atribuída ao efeito da matéria orgânica, que, além de possuir baixa densidade, proporciona a agregação do solo. Vários autores mostraram a desestabilização de agregados e conseqüente aumento da densidade causados pela perda de matéria orgânica devido ao cultivo do solo (Emerson, 1959; Harris et al., 1965; Bauer \& Black, 1981).

$\mathrm{Na}$ condição natural observa-se que a densidade aumentou com a profundidade. Kiehl (1979) atribui este aumento às pressões exercidas pelas camadas superiores sobre as subjacentes, além da movimentação de material fino dos horizontes superiores para os inferiores, reduzindo os espaços porosos e aumentando a densidade, principalmente para os podzólicos, como neste caso.

A atividade dos microrganismos do solo também foi alterada pelo cultivo do solo (Figura 12). Somente na camada superficial $(0-20 \mathrm{~cm})$, ocorreram diferenças significativas na atividade microbiana entre as coberturas vegetais. Nessa profundidade, na média, as amostras provenientes do solo sob mata apresentaram atividade microbiana significativamente maior do que aquelas provenientes do solo cultivado. As duas posições consideradas dentro da cultura não apresentaram diferenças significativas entre si neste parâmetro. 


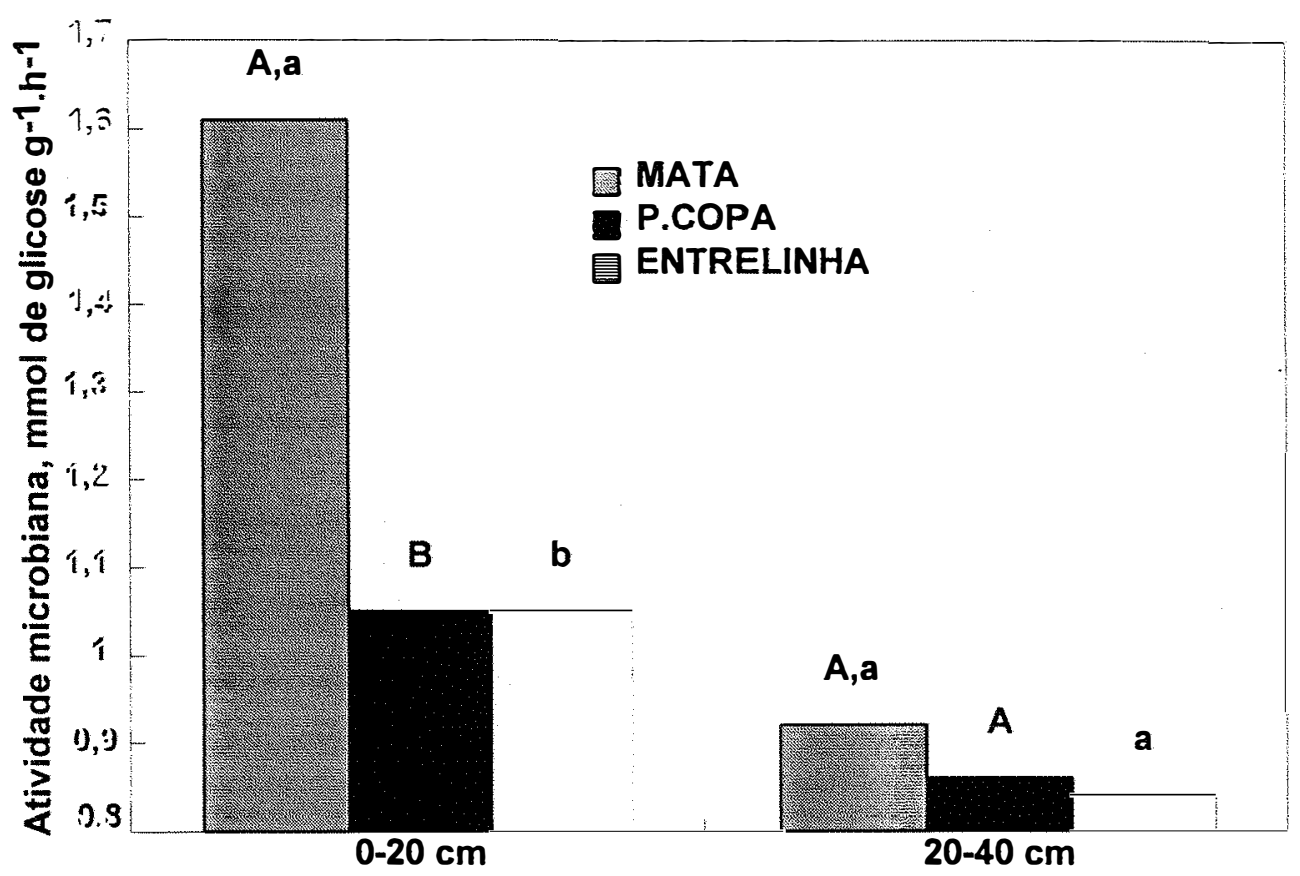

Figura 12 - Valores médios de atividade microbiana nas profundidades 0-20 e 20-40c m , para os três locais considerados. As letras maiúsculas representam o resultado da comparação de médias (teste $\underline{t}$ a $5 \%$ ) entre a mata e a área sob cultivo na posição da projeção da copa. As letras minúsculas representam o resultado da comparação de médias (teste ț a 5\%) entre a mata e a área sob cultivo na posição da entrelinha.

Pode-se supor que a atividade microbiana no solo cultivado foi limitada pela redução na matéria orgânica disponível, cujos teores também não diferiram nas duas posições consideradas dentro da cultura (Figuras 10 e 12). Entretanto, os microrganismos não dependem só da energia e do carbono. O material celular é constituído de diversos elementos, como cálcio, magnésio, fósforo, nitrogênio, que devem estar disponíveis no meio ambiente, de modo a permitir o seu desenvolvimento e multiplicação (Hunter, 1972). A atividade microbiana está intimamente ligada aos fatores físicos e químicos do solo, sendo portanto afetada indiretamente pelo manejo do solo, pelas práticas culturais e pela profundidade. A redução da atividade microbiana 
com a profundidade (Figura 12), mais acentuada na área sob mata, provavelmente está relacionada ao decréscimo natural dos teores de matéria orgânica no perfil do solo, mais acentuado naquela condição.

A importância relativa de cada variável analisada pode ser identificada através dos valores de t obtidos. Valores superiores a 2,1 indicaram diferença significativa entre os dois locais comparados ao nível de $5 \%$ de probabilidade. Quanto maior o valor de $\mathrm{t}$ (valor absoluto) obtido, maior foi a diferença ocorrida. Na Figura 13 encontram-se dispostos os valores de t obtidos para cada variável estudada, nas profundidade $0-20 \mathrm{~cm}$ e 20-40 cm. Nota-se, no geral, que os efeitos da implantação da cultura da laranja foram mais acentuados na camada $0-20 \mathrm{~cm}$. A estrutura do solo, quantificada através da densidade do solo, foi a variável mais alterada pelo cultivo. Para a profundidade de 0-20 $\mathrm{cm}$, a comparação entre a mata e a entrelinha da cultura resultou em $t=8,95$, enquanto que para a comparação entre mata e projeção da copa das plantas $t=8,87$. A elevação da Ds pelo cultivo de citros sugeriu que a qualidade física do solo pode estar comprometendo o potencial máximo de produção de laranja nas áreas estudadas. A compactação do solo associada com a elevação da densidade do solo implica em deterioração de propriedades físicas do solo diretamente relacionadas à produtividade de citros, tais como a resistência do solo à penetração e aeração (Abercrombie \& Du Plessis, 1995).

A redução dos teores de matéria orgânica e da CTC foram bastante significativos na área cultivada, sendo pouco influenciadas pela posição considerada dentro da cultura. Por outro lado, nota-se que as variáveis $\mathrm{pH}, \mathrm{P}$ e V\% são bastante sensíveis à variação na posição considerada. Os valores de t obtidos para estes dois parâmetros na comparação entre mata e entrelinha da cultura foram inferiores a 2,1 nas duas profundidades, portanto não havendo diferença significativa. O mesmo não ocorre quando a comparação foi feita entre mata e projeção da copa das plantas, onde foram obtidos valores de $t=6,32$ e $\mathrm{t}=4,03$ para $\mathrm{pH}$ e $\mathrm{t}=6,49$ e $\mathrm{t}=4,13$ para $\mathrm{V} \%$, nas profundidades $0-20$ e $20-40 \mathrm{~cm}$, respectivamente. Dentre as variáveis associadas a fertilidade do solo, é importante 
ressaltar que os teores de $\mathrm{P}$ contidos no solo sob mata são limitantes para a cultura do citros.

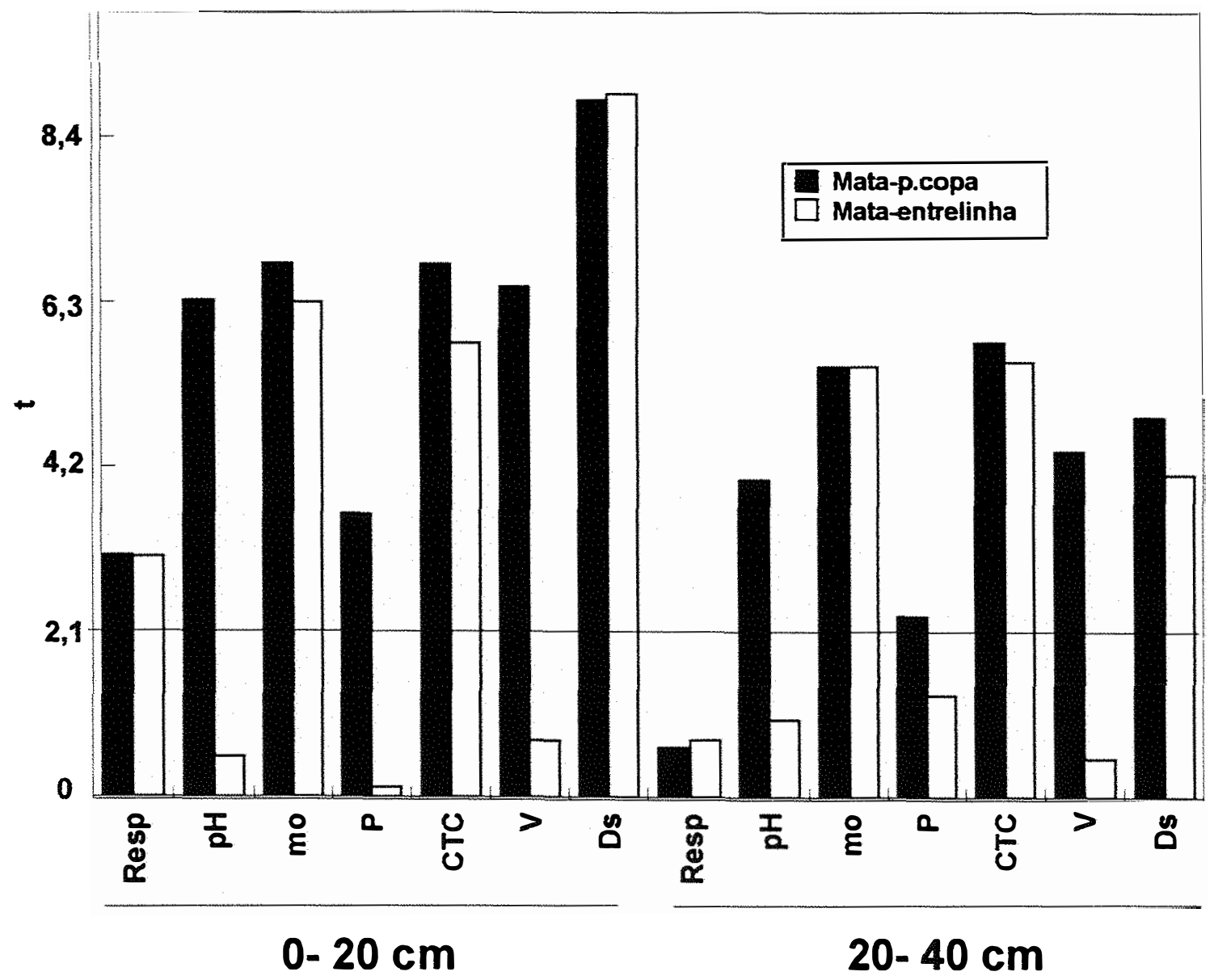

Figura 13 - Valores de t para as variáveis estudadas 


\section{CONCLUSÕES}

A retirada da mata e o cultivo da laranjeira por dezoito anos alterou com intensidades diferentes as propriedades físicas, químicas e microbiológicas do solo, principalmente na camada $0-20 \mathrm{~cm}$.

$\mathrm{O}$ cultivo da laranjeira provocou redução no $\mathrm{pH}$, na saturação por bases, no teor de matéria orgânica, na CTC do solo e na atividade microbiana.

Houve aumento do teor de $\mathrm{P}$ somente na projeção da copa das plantas e da densidade do solo nas duas posições estudadas.

A estrutura do solo, quantificada através da densidade do solo, foi a variável mais alterada pelo cultivo, seguida da CTC e quantidade de matéria orgânica. 


\section{REFERÊNCIAS BIBLIOGRÁFICAS}

AINA, P.O. Soil changes resulting from management practices in Western Nigeria. Soil Science Society of America Journal, v.43, n.1, p.173-177, 1979.

ABERCROMBIE; R.A.; DU PLESSIS, S.F. The effect of alleviating soil compaction on yield and fruit size in an established Navel orange orchad. Journal South Africa Society Horticultural Science, v. 5, n. 2, p. 85-89, 1995.

ALLISON, F.E. Soil aggregation - Some facts fallacies as seen by a microbiologist. Soil Science, v.106, n.2, p.136-143, 1968.

ALMEIDA, F.F.M.; CARNEIRO, C.D.R.; BISTRICHI, C.A.; PONÇANO, W.L.; PRANDINI,F.L. Mapa geológico do Estado de São Paulo. Instituto de Pesquisas Tecnológicas do Estado de São Paulo. v.1, São Paulo, 1981. 94p.

ANDERSON, M.A.; BROWNING, G.M. Some physical and chemical properties of six virgin and six cultived Iowa soils. Soil Science Society of America Proceedings, v.14, p.370-374, 1949.

BAUER, A.; BLACK, A.L. Soil carbon, nitrogen and bulk density comparisons in two cropland tillage systems after 25 years and in virgin grassland. Soil Science Society of America Journal, v.45, p.1166-1170, 1981.

BAUER, A.; BLACK, A.L. Quantification of the effect of soil organic matter content on soil productivity. Soil Science Society of America Journal, v.58, p.185-193, 1994. 
BLAKE, G.R.; HARTGE, K.H. Bulk density. In: A. Klute (2 ed.) Methods of soil analisys - Physical and mineralogical methods. ASA - SSSA: Madison, 1986. p. 363-375.

BORGES, A.L.; KIEHL, J.C. Alteração da matéria orgânica de um latossolo amarelo álico de Cruz das Almas (BA), pelo cultivo com frutíferas perenes e mandioca. Revista Brasileira de Ciência do Solo, v.20, p.313-318, 1996.

BORGES, A.L.; KIEHL, J.C. Cultivo de frutíferas perenes e de mandioca sobre as propriedades químicas de um latossolo amarelo álico de Cruz das Almas (BA). Revista Brasileira de Ciência do Solo, v.21, p.341-345, 1997.

BRAMS, E. Continuous cultivation of West African soils: organic matter diminuition and effects of applied lime and phosphorus. Plant and Soil, v.35, p. 401-414, 1971.

BRYAN, O. C. The accumulation and availability of phosphorus in old citrus grove soils. Soil Science, v. 36, p. 249-259, 1933.

CAMARGO, M.N.; KLAMT, E.; KAUFFMAN, J.H. Classificação de solos usada em levantamentos pedológicos no Brasil. Boletim Informativo da Revista Brasileira de Ciência do Solo, v. 12, n. 1, p. 11-33, 1987.

CAMARGO, O.A.; MONIZ, A. C.; JORGE, J.A. \& VALADARES, J.M.A.S. Métodos de análise química, mineralógica e física de solos do Instituto Agronômico de Campinas. Campinas: Instituto Agronômico, 1986. 94p. (Boletim Técnico, 106). 
CAMPOS, B.C.; REINERT, D.J.; NICOLODI, R. RUEDELL, J. \& PETRERE, C. Estabilidade estrutural de um latossolo vermelho escuro distrófico após sete anos de rotação de culturas e sistemas de manejo do solo. Revista Brasileira de Ciência do Solo, v.19, p.99-105, 1995.

CARTER, M.R. Physical properties of some Prince Edward Island soils in relation to their tillage. Canadian Journal of Soil Science, v. 67, p. 473-483, 1987.

CASSEL, D.K. Spatial and temporal variability of soils physical properties followuing tillage of Norfolk loamy sand. Soil Science Society of America Journal, v. 47, p. 196-201, 1983.

CERRI, C.C. Dinâmica da matéria orgânica do solo no agroecossistema cana-de-açúcar. Piracicaba, 1986. 197p. Tese (Livre Docência) - Escola Superior de Agricultura "Luiz de Queiroz", Universidade de São Paulo.

CHAN, K.Y.; MEAD, J.A. Surface physical properties of a sandy loam soil under different tillage practices. Australian Journal of Soil Research, v.26, p.549-559, 1988.

CHAN, K.Y.; ROBERTS, W.P.; HEEMAN, D.P. Organic carbon and associated soil properties of a red earth after 10 years of rotation under different stubble and tillage practices. Australian Journal of Soil Research, v.30, p.71-83, 1992.

CHANG, C.W. Effects of long-time cropping on soil properties in northeastern New Mexico. Soil Science, v.69,p.359-368, 1950. 
CINTRA, F.L.D.; COELHO, Y.S.; CUNHA SOBRINHO, A.P. da. Caracterização física do solos submetido a prática de manejo em pomar de laranja "Baianinha". Pesquisa Agropecuária Brasileira, v.18, n.2, p.173-179, 1983.

CINTRA, F.L.D.; CUNHA, G.A.P.da. Caracterização física de solos cultivados com abacaxi em áreas com diferentes tempos de utilização. Revista Brasileira de Fruticultura, v.9, n.3, p.7-15, 1987.

COMISSÃO DE SOLOS. Levantamento de reconhecimento dos solos do Estado de São Paulo. (Contribuição à carta de solos do Brasil). Boletim Serviço Nacional de Pesquisa Agronômica. Rio de Janeiro: v. 12, 634 p. 1960.

COOTE, D.R.; RAMSEY, J.F. Quantification of the effects of overs 35 years of intensive cultivation on four soils. Canadian Journal of Soil Science, v.63, n.1, p.1-14, 1983.

CORRÊA, J.C.; REICHARDT, K. Alterações de um latossolo da Amazônia Central sob pastagens. In: CONGRESSO BRASILEIRO DE CIÊNCIA DO SOLO, 23., Porto Alegre, 1991. Resumos. Porto Alegre: SBCS/ UFRGS, 1991.p.107.

CUNNIGHAM, R.K. The effect of clearing a tropical forest soil. Journal of Soil Science, v. 14, n. 2, p. 334-345, 1963.

CURTIS, R.O.; POST, B.W. Estimating bulk density from organic matter content in some Vermont forest soils. Soil Science Society of America Proceedings, v.28, p.285-286, 1964.

DA ROS, C.O.; SECCO, D.; FIORIN, J.E.; PETRERE, C.; CADORE, M.A.; PASA, L. Manejo do solo a partir de campo nativo: efeito sobre a forma e estabilidade da 
estrutura ao final de cinco anos. Revista Brasileira de Ciência do Solo, v.21, n.2, p.241-247, 1997.

ELLIOT, E.T. Aggregate structure and carbon, nitrogen, and phosphorus in native and cultivated soils. Soil Science Society of America Journal, v.50, n.3, p.627-633, 1986.

DEMATTÊ, J.L.I. Estudo agrotécnico das terras da fazenda Cambuhy, Matão Estado de São Paulo. Piracicaba: ESALQ, Depto. Ciência do Solo, 1980.

EMPRESA BRASILEIRA DE PESQUISA AGROPECUÁRIA. Mapa de solos do Brasil. Rio de Janeiro: EMBRAPA, 1981.

EMERSON, W.W. The structure of soil crumbs. Journal of Soil Science, v. 10, p. 235-244, 1959.

FAO. Statistical series, v. 48, p. 61, 1995.

FIALHO, J.F.; BORGES, A.C.; BARROS, N.F. Cobertura vegetal e as características químicas e físicas e atividade da microbiota de um latossolo vermelho-amarelo distrófico Revista Brasileira de Ciência do Solo, v.15, p.21-28, 1991.

FONSECA, S. Propriedades físicas, químicas e microbiológicas de um Latossolo Vermelho-Amarelo sob eucalipto, mata natural e pastagem. Viçosa, 1984. 78p. Dissertação (M.S.) - Universidade Federal de Viçosa.

FREITAS, J.R.; NASCIMENTO, V.F.; VOSE, P.B.; RUSCHEL, A.P. Estimativa da atividade da microflora heterotrófica em solo terra roxa estruturada usando respirometria com glicose $-{ }^{14} \mathrm{C}$. Energia Nuclear na Agricultura, v.1, n.2, p. 123130, 1979. 
GODEFROY, J.; JACQUIN, F. Relation entre la stabilité structurale des sols cultivés et le apports organiques en conditions tropicales;comparasion avec les sols forestiers. Fruits, v.30, n.10, p.595-612, 1975a.

GODEFROY, J.; JACQUIN, F. Influence de la végétation sur l'humification en sol ferrallique. Chiers Orstom. Sér. Pédologie, v.23, n.3-4, p.279-298, 1975 b.

GOLDING, A.; LAVKULICH, L.M. Historical land clearing in the fraser lowland of British Columbia and Washington State: l. Effects on soil genesis. Soil Science Society of America Journal, v.52, p.467-473, 1988.

GRISI, B.M.; SANTOS, O.M. Respiração edáfica em vegetação natural e submetida à queima, num ecossistema de floresta tropical no sul da Bahia. Revista Brasileira de Biologia, v.38, n.3, p.579-586, 1978.

GRUPO PAULISTA DE ADUBAÇÃO E CALAGEM PARA CITROS. Recomendações de adubação e calagem para citros no Estado de São Paulo. Laranja, v. 15, n.2, 1994. Edição especial.

HAJABBASI, M.A.; JALALIAN, A.; KARIMZADEH, H.R. Deforestation effects on soil physical and chemical properties, Lordegan, Iran. Plant and Soil, v.190, p.301308, 1997.

HAMMEL, J.E. Long-term tillage and crop rotation effects on bulk density and soil impedance in Northen Idaho. Soil Science Society of Americam Journal, v. 53, p. 1515-1519, 1989. 
HARRIS, R.F. ; CHESTER, G. \& ALLEN, O.N. Dynamics of soil aggregation. Advanced Agronomy, v. 18, p. 107-160, 1965.

HILL, D.E. The storage of moisture in Connecticut soils. Soil Science Society of America Proceedings,v.32, p.866-870, 1959.

HUNTER, S.H. Inorganic nutrition. Annual Review of Microbiology, v.26, p. 313346, 1972.

INSTITUTO DE ECONOMIA AGRÍCOLA. Os números da citricultura. São Paulo: IEA, 1997. 28p.

ISMAIL, I.; BLEVINS, R.L.; FRYE, W.W. Long-term no-tillage effects on soil properties and continuous corn yelds. Soil Science Society of America Journal, v.58, p.193-198, 1994.

JAMISON, V.C. Changes in air-water relationships due to structural improvement of soils. Soil Science, v.76,p.143-151, 1953.

JAMISON, V.C. Pertinent factors governing the availability of soil moisture to plants. Soil Science, v.81,p.459-469, 1956.

JAMISON, V.C.; KROTH, E.M. Available moisture storage capacity in relation to textural composition and organic matter content of several Missouri soils. Soil Science Society of America Proceedings,v.22, p.189-192, 1958.

KIEHL, E.J. Manual de edafologia - relações solo-planta. São Paulo:Agronômica Ceres, 1979, 264p. 
KLUTE, A. Water retention : Laboratory Methods. In: A. KLUTE (Ed.) Methods of soil analisys - Physical and mineralogical methods. ASA - SSSA: Madison, 1986. p. 363-375.

LEITÃO-FILHO, H.F. Aspectos taxonômicos das florestas do Estado de São Paulo. In: Congresso Nacional sobre Essências Nativas. Silvicultura em São Paulo, 1982. Anais. 16A, v.1, p.197-206.

LAVKULICH, L.M.; ROWLES, C.A. Effect of different land use practices on a British Columbia Spodosol. Soil Science, v. 111, p. 323-329, 1971.

LAWS, W.D.; EVANS, D.D. The effect of long-time cultivation on some physical and chemical properties of two Rendzina soils. Soil Science Society of America Proceedings, v. 4, p. 15-19, 1949.

LEPSCH, I.F.; MENK, J.R.F.; OLIVEIRA, J.B. Carbon storage and other properties of soils under agriculture and natural vegetation in São Paulo State, Brazil. Soil Use and Management, v.56, p.34-42, 1994.

LEPSCH, I.F. Influência do cultivo de Eucalyptus e Pinus nas propriedades químicas de solos sob cerrado. Revista Brasileira de Ciência do Solo, v.4, n.2, p.103-107, 1980.

LIMA, J.M.J.C. Alterações de propriedades de solos cultivados com cana-de-açucar. Piracicaba, 1995. 173p. Tese (Doutorado) - Escola Superior de Agricultura "Luiz de Queiroz", Universidade de São Paulo. 
LOPES, A.S.; COX, F.R. A survey of the fertility status of sulface soils under "cerrado" vegetation in Brazil. Soil Science Society of America Journal, v.41, n.4, p. 742$747,1977$.

LUZ, P.H.C. Efeitos de modos de aplicação e incorporação de calcário e gesso em pomares de citros. Piracicaba, 1995. 159p. Tese (Doutorado) - Escola Superior de Agricultura “Luiz de Queiroz”, Universidade de São Paulo.

MACHADO, J.A.; BRUM, A.C.R.de. Efeito de sistemas de cultivo em algumas propriedades físicas do solo. Revista Brasileira de Ciência do Solo, v.2, n.2, p.8184, 1978.

MACHADO, J.A.; SOUZA, D.M.de.; BRUM, A.C.R.de. Efeiro de anos de cultivo convencional em propriedades físicas do solo. Revista Brasileira de Ciência do Solo, v.5, n.3, p.187-189, 1981

MARTEL, Y.A.; DESCHENES, J.M. Les effects de la mise en culture et de la prairie prolonges sur le carbone, I'azote et la structure de quelques sols due Quebec. Canadian Journal of Soil Science, v.56, p.373-383, 1976.

MBAGWU, J.S.C.; BAZZOFFI, P. Stability of microaggregates as influenced by antecedent moisture content, organic waste amendment and wetting and drying cycles. Catena, v.15, p.565-576, 1988.

MILLER, R.H.; NICHOLAIDES, J.J.; SANCHEZ, P.A.; BANDY, D.E. Soil organic matter considerations in agricultural systems of the humid tropics. In: COLÓQUIO REGIONAL SOBRE MATÉRIA ORGÂNICA DO SOLO, 1, Piracicaba, 1982. Anais. Piracicaba:CENA, 1982. p.105-110. 
MONREAL, C.N.; JANZEN, H.H. Soil organic carbon dynamics after 80 years of cropping a Dark Brown Chernozem. Canadian Journal of Soil Science, v.73, p.133-136, 1993.

MORAES, J.F.L.; VOLKOFF, B.; CERRI,C.C.; BERNOUX,M. Soil properties under Amazon forest and changes due to pasture installation in Rondônia, Brazil. Geoderma, v.70, p. 63-81, 1996.

PRATT, P.F.; JONES, W.W.; CHAPMAN, H.D. Changes in phosphorus in an irrigated soil during 28 years of differential fertilization. Soil Science, v. 36, p. 295-306, 1956.

QUAGGIO, J.A. Respostas da laranjeira valência (Citrus sinensis L. Osbeck) sobre limoeiro cravo (Citrus limonia L. Osbeck) a calagem e ao equilíbrio de bases num latossolo vermelho escuro de textura argilosa. Piracicaba, 1991. 107p. Tese (Doutorado) - Escola Superior de Agricultura "Luiz de Queiroz", Universidade de São Paulo.

QUAGGIO, J.A. Variações na interpretação de resultados de análise de solo em função do local de amostragem na citricultura. In: REUNIÃO BRASILEIRA DE FERTILIDADE DO SOLO E NUTRIÇÃO DE PLANTAS, Petrolina (PE), 1994. Anais. Petrolina: SBCS, 1994. p. 405-406.

QUAGGIO, J.A. Análise de solo para citros: métodos e critérios para interpretação de resultados. In: SEMINÁRIO INTERNACIONAL DE CITROS - NUTRIÇÃO E ADUBAÇÃO, 4º , Bebedouro, 1996. Anais. Campinas, Fundação Cargill, 1996. p. 95-113. 
RAIJ, B. van; QUAGGIO, J.A. Métodos de análise de solo para fins de fertilidade. Campinas: Instituto Agronômico, 1983. 31p. (Boletim Técnico, 81)

RAIJ, B. van. Fertilidade do solo e adubação. Piracicaba: Agronômica Ceres, Potafos, 1991.343p.

ROBERTS, W.P.; CHAN, K.Y. Tillage induced increases in carbon dioxide loss from soils. Soil Tillage Research, v.17, p.143-151, 1990.

ROVIRA, A.D.; GREACEN, E.L. The effect of aggregate disruption on the activity of microorganisms in the soil. Australian Journal of Agricultural Research, v.8,p.659-679, 1957.

RUSSEL, E.J.; RUSSEL, R.W. Soil conditions and plant growth. 9.ed. London: Longmam \& Green, 1961. 770p.

SALONIUS, P.O. Microbiological response to fertilizer treatments in organic forest soils. Soil Science, v.114, n.1, p.12-19, 1972.

SALTER, P.J.; BERRY, G.; WILLIAMS, J.B. The influence of texture on the moisture characteristics of soils. Journal of Soil Science, v.17, p.93-98, 1966.

SANCHEZ, P.A.; VILLACHICA, J.H.; BANDY, D.E. Soil Fertility dynamics after cleaning a tropical rainforest in Peru. Soil Science Society of America Journal, v.47, p.1171-1178, 1983.

SANCHEZ, P.A. Properties and management of soils in the tropics. New York: Wiley, 1976. 619p. 
SANTOS, O.M.; GRISI, B.M. Efeito do desmatamento na atividade dos microrganismos de solo de terra-firme na Amazônia. Acta Amazônica, v.11, n.1, p.97-102, 1981.

SAS INSTITUTE. SAS/STAT procedure guide for personal computers. Version 5 ed. SAS Inst., Cary, NC. 1991.

SCHIMEL, D.S.; COLEMAN, D.C.; HORTON, K.A. Soil organic matter dynamics in paired rangeland and cropland toposequences in north Dakota. Geoderma, v.36, p.201-214, 1985.

SCOTT, H.D.; WOOD, L.S. Impact of crop production on the physical status of a typic Albaqualf. Soil Science Society of America Journal, v.53, p.1819-1825, 1989.

SELBACH, P.A. Acidez dos solos e atividade microbiana. In: SEMINÁRIO SOBRE CORRETIVOS DA ACIDEZ DO SOLO, 2., Santa Maria, 1989. Anais. Santa Maria: UFSM, 1989. p.62-73.

SHARMA, M.L.; UEHARA, G. Influence of soil structure on water relations in Low Humic Latosols: I. Water retention. Soil Science Society of America Proceedings, v.32, p.765-770, 1968.

SHERMAN, G.D.; ALEXANDER, L.T. Characteristics and genesis of Low Humic Latosols. Soil Science Society of America Proceedings, v.23, p.168-170, 1959.

SILVA, L.F.da. Alterações edáficas em "solos de tabuleiro" (Haplorthxs) por influência do desmatamento, queima e sistemas de manejo. Revista Theobroma, v.11,n.1, p.5-19, 1981. 
SILVA, M.S.L.; RIBEIRO, M.R. Influência do cultivo contínuo da cana-de-açúcar em propriedades morfológicas e físicas de solos argilosos de tabuleiro no Estado de Alagoas. Revista Brasileira de Ciência do Solo, v.16, p.397-402, 1992.

STEVENSON, J.F. Humus chemistry, genesis, composition, reaction. New York: John Wiley \& Sons, 1982. 443p.

TERSI, F.E.A.; ROSA, S.M. A subsolagem no manejo de solo para os pomares de citros, Laranja, v. 16, n. 2, p. 289-298, 1995.

TISDALL, J.M.; OADES, J.M. Organic matter and water-stable aggregates in soils. Journal of Soil Science, v.33, n.2, p.141-163, 1982.

TSAI, S.M.; BARAIBAR, A.V.L.; ROMANI, V.L.M. Efeito de fatores do solo. In: CARDOSO, E.J.B.N.; TSAI,S.M.; NEVES, M.C.P. Microbiologia do solo. Campinas: Sociedade Brasileira de Ciência do Solo, 1992. cap.5, p.59-72.

VITTI, G.C.; LUZ, P.H.C.; LEÃO, H.C. \& SILVA, M.M. Técnicas de utilização de calcário e gesso na cultura dos citros. In: SEMINÁRIO INTERNACIONAL DE CITROS - NUTRIÇÃO E ADUBAÇÃO, 4º , Bebedouro, 1996. Anais. Campinas: Fundação Cargill, 1996. p. 131-160.

VOLKOFF, B. La matiére organique des sols ferrallitiques du nordeste du Brésil. Chiers Orstom. Sér. Pédologie, v.15, n.3, p.275-290, 1977. 